\title{
Exchange of Carbon Dioxide in the Pregnant Rhesus Monkey: Multicompartmental Analysis of Carbon Dioxide Kinetics
}

\author{
Kotaro Suzukr, Albert A. Plentr, * and Karlis Adamsons \\ From the Department of Obstetrics and Gynecology, Columbia University, \\ College of Physicians and Surgeons, New York 10032
}

\begin{abstract}
A в S T R A C T The exchange of carbon dioxide in the pregnant rhesus monkey has been studied quantitatively using sodium bicarbonate $-{ }^{14} \mathrm{C}$ and applying the model of a system of seven compartments. The transfer rates among the various compartments, compartment sizes, and the rate of production of carbon dioxide by fetus and mother were determined with a computer programmed to fit the theoretical model to the data by adjusting the parameter values of the model until a "best fit" was obtained. It was confirmed that the exchange of carbon dioxide between fetal and maternal blood across the placenta is rapid, that between fetal blood and amniotic fluid is slow, and that there is no appreciable exchange between maternal blood and amniotic fluid. The mean net production of $\mathrm{CO}_{2}$ by fetus was $0.476 \pm 0.0402 \mathrm{mmoles} / \mathrm{kg} \cdot \mathrm{min}$, and that by mother was $0.373 \pm 0.0279 \mathrm{mmoles} / \mathrm{kg} \cdot \mathrm{min}$.
\end{abstract}

\section{INTRODUCTION}

Since the carbohydrates are the principal source of energy of the fetus (1), carbon dioxide is the most important end product of fetal energy metabolism. Thus, the amount of carbon dioxide transferred from the fetus to the mother can be used as an indicator of its metabolic activity. The standard methods of determining the metabolic rate of the fetus are based on measurements of oxygen consumption. This requires quantitation of umbilical or uterine blood flow and difference in oxygen content between artery and vein. Accurate measurement of these variables without disturbing the normal state is difficult, if not impossible. The principal objective of this study was to determine $\mathrm{CO}$, output of the fetus (net transfer of $\mathrm{CO}$, from fetus to mother) without the knowledge of flow rates and arteriovenous differences by

\footnotetext{
* Deceased.

Received for publication 22 October 1968 and in revised form 18 April 1969.
}

means of a ${ }^{14} \mathrm{C}$ distribution technique. Furthermore, it was anticipated that knowledge of $\mathrm{CO}_{2}$ exchange between the various maternal and fetal compartments would be of value in the assessment of the acid-base state of the fetus during labor.

$\mathrm{CO}_{2}$ discussed here denotes the total $\mathrm{CO}_{2}$ which exists in various forms in the animal, such as the physically dissolved $\mathrm{CO}_{2}$, carbonic acid, bicarbonate, and carbamino compounds, and which can be measured as acid-volatile $\mathrm{CO}_{2}$.

\section{METHODS}

Materials. Two nonpregnant adult and four pregnant rhesus monkeys (Macaca mulatta) near term were used in this study. The nonpregnant animals were used in order to estimate the minimal number of compartments regarding the distribution of carbon dioxide. The rhesus monkey was chosen because of the similarity of placental structure and the relative size of body compartments of the fetus and mother with those of the human. In addition, the presence of a secondary placenta enables one to obtain fetal blood from interplacental vessels without rupturing the amnion. In the rhesus monkey the umbilical vessels reaching the chorionic plate divide into numerous branches supplying the primary placenta. One or more trunks consisting usually of two arteries and one vein bypass it to reach the secondary lobe. The interplacental vessels course in the potential space between amnion and chorion, and can be readilly isolated. This morphologic arrangement has been exploited in various animals, and was first applied to the rhesus monkey by Reynolds, Paul, and Huggett (2). Table I gives details of materials studied.

Experimental design. The mothers were anesthetized with Sernylan ${ }^{1}$ ( $2 \mathrm{mg} / \mathrm{kg}$ of body weight intramuscularly) about $30 \mathrm{~min}$ before the operative procedure. Body temperature was maintained at $37^{\circ} \mathrm{C}$ by a heat lamp. In the nonpregnant animals a catheter was inserted into a calf vein of each leg with the tip of the catheter threaded upward into the inferior vena cava, one with the tip above renal veins for injection of the isotope and the other with the tip below renal veins for sampling of blood. In the pregnant monkeys, after bilateral

${ }^{1}$ 1-(1-phenylcyclohexyl) piperidine hydrochloride. Parke, Davis \& Co., Detroit, Mich. 
TABLE I

Vital Statistics

\begin{tabular}{cccc}
\hline $\begin{array}{c}\text { Experi- } \\
\text { ment } \\
\text { No. }\end{array}$ & Monkey No. & Gestation & Weight \\
\hline & & days & $k g$ \\
& 406 & Nonpregnant & 4.6 \\
I & 397 & Nonpregnant & 5.3 \\
II & 319 & 152 & 8.5 \\
III & 408 & 153 & 5.6 \\
IV & 428 & 157 & 6.8 \\
& 408 & 146 & 6.18 \\
& & - & - \\
& Mean of 4 pregnant & 152 & 6.8 \\
& monkeys & & \\
\hline
\end{tabular}

catheterization of a calf vein with the tips of catheters threaded upward into the inferior vena cava in the same fashion, a midline incision was made and the uterus was delivered through the abdominal incision. Placental margins and interplacental vessels were located by transillumination and were marked on the uterine serosa with silver nitrate. A small incision was made over the interplacental vessels and either the artery or the vein was isolated. A Silastic T-shaped catheter was inserted into the vessel and secured with silver rings (3). The myometrial incision was then approximated with interrupted sutures and the uterus was returned to the abdominal cavity. Whenever possible, the interplacental artery was chosen because of greater facility to obtain blood samples. In experiment IV in which the tracer was injected into the fetal circulation, two interplacental vessels at two different sites, one artery and one vein, were catheterized (Fig. 1). In all preparations a separate catheter was introduced into the amniotic cavity.

The isotope used was a ${ }^{14} \mathrm{C}$-labeled sodium bicarbonate with an activity of $20 \mathrm{mCi} / \mathrm{mmole}$. The total dose employed in each experiment was $1.0 \mathrm{mCi}$ dissolved in a volume of 1.0 $\mathrm{ml}$ of normal saline. This amount of ${ }^{14} \mathrm{C}$ was chosen to provide a readily measurable quantity of the isotope in a 1 to $10^{\circ}$ dilution.

In the two experiments with nonpregnant monkeys the isotope was injected into vena cava above renal veins in less than $30 \mathrm{sec}$, and serial blood samples were collected from vena cava below renal veins over the subsequent $4 \mathrm{hr}$, at first every few minutes and then at longer intervals.

In the experiments with pregnant monkeys, in three instances (experiments I, II, III) the tracer was injected into the maternal vena cava above renal veins and in one experiment (experiment IV) it was injected directly into the fetal circulation (interplacental vein). Samples of maternal blood from vena cava below renal veins, fetal blood from interplacental artery, and amniotic fluid were collected in the same fashion as above over 4-5.5 hr. In each collection of either blood or amniotic fluid the initial portion of the sample was withdrawn in a separate syringe which was not used for determination of the isotope but was saved for replacement. A fresh $1 \mathrm{ml}$ disposable syringe was then attached and $0.5 \mathrm{ml}$ of sample collected. The original $1 \mathrm{ml}$ of blood or amniotic fluid which had been withdrawn to clear dead space was then reinjected. The sample was transferred under oil into a $2 \mathrm{ml}$ heparinized tube containing sodium fluoride. For the collection of amniotic fluid, a nonheparinized tube was used.

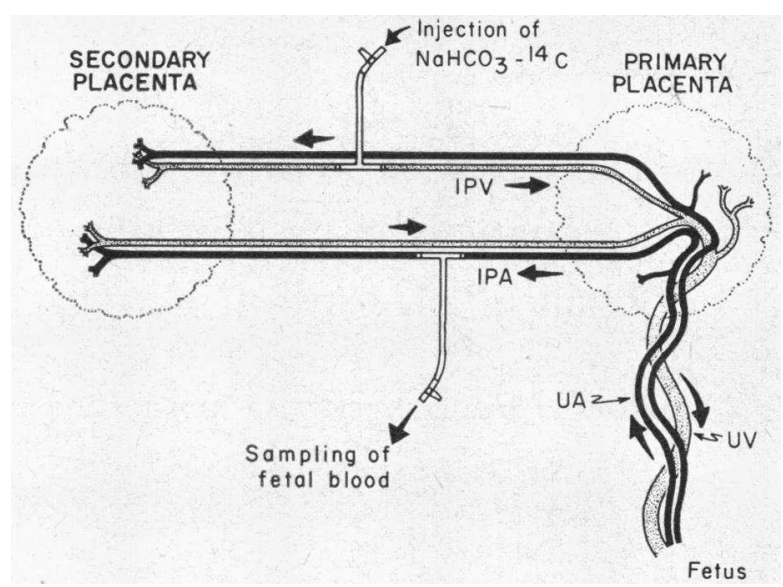

FIGURE 1 Schematic presentation of the vascular structures of the placentas in the rhesus monkey and the location of catheters in the fetal vessels. IPV, interplacental vein; IPA, interplacental artery; UV, umbilical vein; UA, umbilical artery; $\rightarrow$, direction of blood flow. Only IPA catheter was used for sampling the fetal blood in experiments I, II, and III.

Before the determination of the radioactivity of the sample, the material had to be transformed into carbon dioxide gas. The total carbon dioxide content of each sample, $0.2 \mathrm{ml}$ of whole blood or amniotic fluid, was determined according to the procedures described by Peters and Van Slyke (4). Collection of ${ }^{14} \mathrm{CO}_{2}$ for scintillation counting was done according to the procedure of Van Slyke as modified by Weyman, Williams, and Plentl (5), using phenethylamine as absorbent. Radioactivity of ${ }^{14} \mathrm{C}$ was measured by the use of liquid scintillation counter (Nuclear-Chicago 720 series), at $4^{\circ} \mathrm{C}$ against a background of $20-22 \mathrm{cpm}$. Each sample was counted three times, each time either for $80 \mathrm{~min}$ or up to one million counts, whichever occurred first. The counting error was less than $1 \%$. The value was corrected for counting efficiency (about $60 \%$ ) which was obtained from the channels ratio; thus the average result could be expressed as disintegrations per minute per $0.2 \mathrm{ml}$ of sample. Knowing the total $\mathrm{CO}_{2}$ content in the sample the specific activity was expressed as disintegrations per minute per millimole of $\mathrm{CO}_{2}$. The fractional amount of the tracer in each compartment was expressed as a function of time from the specific activity. This was derived by dividing the product of $\mathrm{CO}_{2}$ content and each specific activity in a compartment by the number of disintegrations per minute of the injected tracer (in this case $1 \mathrm{mCi}=2.2 \times 10^{\circ} \mathrm{dpm}$ ). Maternal plasma volume was determined by dilution method using Evans blue (T-1824) as an indicator, and a Beckman model DU spectrophotometer. for measurement of absorbance. With the knowledge of the concentration of red blood cells the maternal blood volume was calculated. Fetal blood volume was estimated to be $10 \%$ of fetal weight and $30 \%$ of placental weight. Amniotic fluid volume was determined by dilution method using $1 \mathrm{ml}$ of radioactive iodinated serum albumin (RISA) (6) of low activity (approximately $0.5 \mathrm{uCi} / \mathrm{ml}$ ) which was injected into amniotic fluid. The withdrawn specimen of amniotic fluid was counted in a NuclearChicago well-type scintillation counter equipped with a model 186 decade scaler. The theory of Berman and Schoenfeld (7) was applied for analysis of data taking advantage of a general purpose computer program developed by Berman (8) (SAAM-22; Simulation, Analysis and Modeling). 


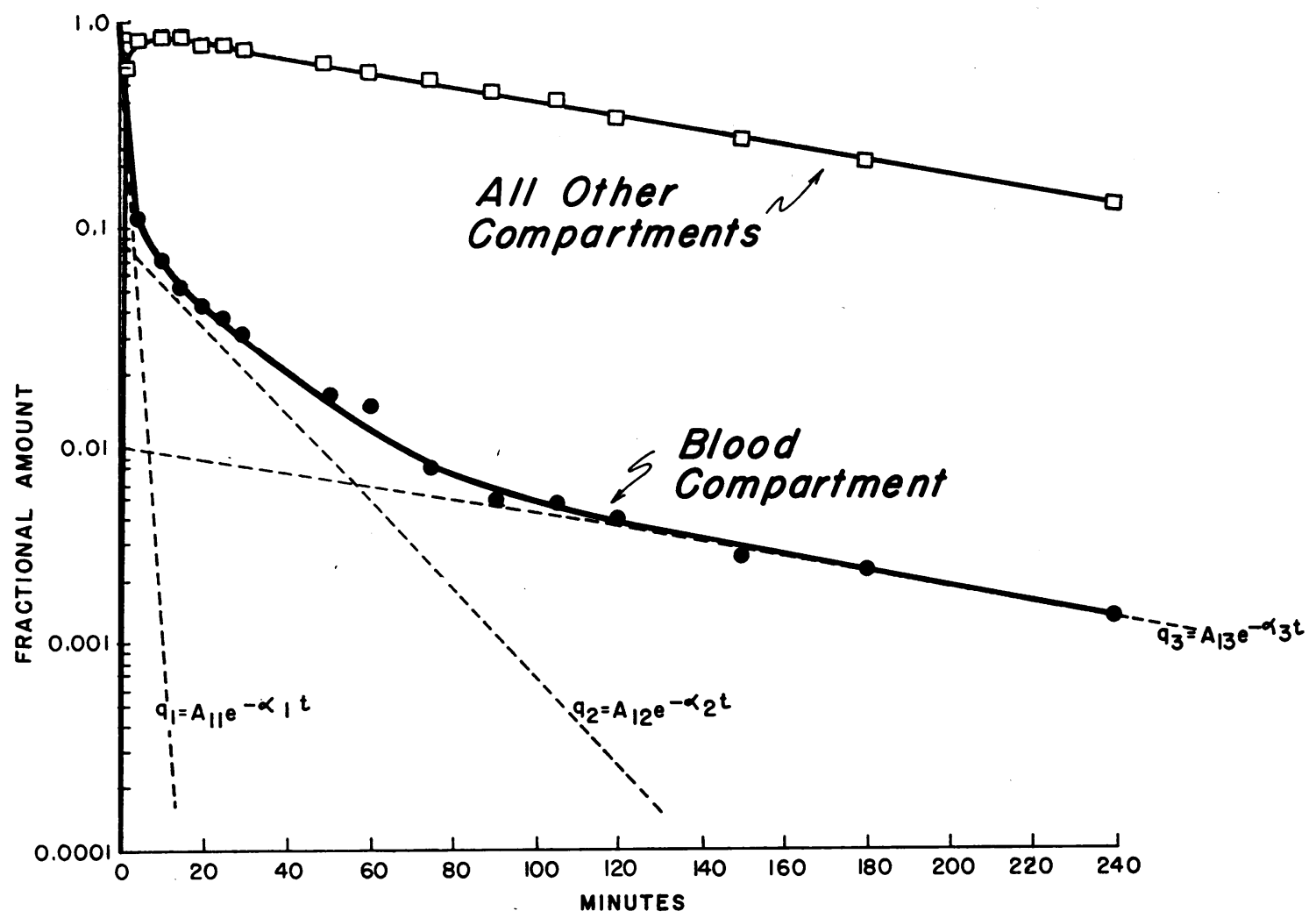

Figure 2 Fractional amount of ${ }^{14} \mathrm{C}$ in blood and all other body compartments of a nonpregnant monkey as function of time. Three principal compartments are identified $\left(q_{1}, q_{2}\right.$ and $\left.q_{2}\right)$. The coefficients $A_{11}, A_{12}$ and $A_{13}$ (intercepts) and the exponential constants $\alpha_{1}, \alpha_{2}$, and $\alpha_{3}$ (slopes) have been determined by the "peeling"technique.

\section{RESULTS}

Observed data. The curves obtained in the two experiments with nonpregnant monkeys were nearly identical. One of them is reproduced in Fig. 2, where the theoretic isotope content for ${ }^{14} \mathrm{C}$ at time zero (to) is arbitrarily set equal to unity, and the fractional amount in the blood compartment and all other compartments in the rest of the body are expressed as a function of time on a semilogarithmic scale. The data are also given in Appendix I. The curves obtained in the four experiments with pregnant animals in which the isotope was injected into either maternal or fetal blood stream were also nearly identical; two of them are reproduced in Fig. $3 \mathrm{~A}$ and $\mathrm{B}$ and Fig. $4 \mathrm{~A}$ and $\mathrm{B}$. The concentration of ${ }^{21} \mathrm{C}$ is given as a function of time and is expressed as specific activity (Figs. $3 \mathrm{~A}$ and $4 \mathrm{~A}$ ) and as fractional amount (Figs. $3 \mathrm{~B}$ and $4 \mathrm{~B}$ ). The specific activity in the primary compartment at to is estimated by extrapolation based on the knowledge of the blood volume and the amount of tracer injected. As an example the data of fractional amount and its statistical weight of experiment $I$ is given in Appendix II.
Theoretical considerations. There are two basic assumptions inherent in the present analysis: first, that $\mathrm{CO}$ pool in each animal is in a steady state, and second, that the system is compartmentalized regarding the constituents of the $\mathrm{CO}$ s system. The first assumption is reasonable since the studies were carried out while the animal was under light sedation at least $1 \mathrm{hr}$ after the completion of the surgical procedure; furthermore, there were no significant changes in the total $\mathrm{CO}_{2}$ in each sample of maternal and fetal blood and amniotic fluid throughout the study period. The second assumption also appears valid for the following reasons. First, there are several reports which give evidence that "compartmentalized system" can be assumed regarding the distribution of $\mathrm{CO}$, and its homologues. Steele (9) described a method for calculating the distribution of bicarbonate ${ }^{14} \mathrm{C}$ measured as total acid-volatile ${ }^{{ }^{14}} \mathrm{CO}$, in an idealized "three compartment" cat and found a satisfactory agreement between the observed values and those predicted for such a model. He assumed a central compartment representing the circulating blood and two other discrete peripheral compartments consisting of the solid carbonate of bone and the bicarbonate of the soft 
tissues. Singer et al. (10) showed that in man equilibrium in the distribution of $\mathrm{NaHCO}_{3}$ between blood and interstitial fluid possibly including collagen was reached in about $30 \mathrm{~min}$, whereas that between interstitial fluid and intracellular fluid required a much longer time interval. Certainly the infused bicarbonate must have been distributed homogeneously in the primary blood compartment within the first few minutes after the completion of infusion. Their studies indicate the existence of at least three compartments regarding the distribution of the bicarbonate. The previous reports from this laboratory by Friedman et al. (11) and Plentl and Friedman (12) have given evidence that in the pregnant animal there are several distinct compartments such as maternal blood, maternal extravascular pool, fetal blood, fetal extravascular pool, and amniotic fluid with regard to the distribution of acid-volatile ${ }^{14} \mathrm{CO}$ after the injection of bicarbonate- ${ }^{14} \mathrm{C}$. Furthermore such an assumption is consistent with the present data which can be clearly broken down into at least three exponential components (Figs. 2, 3, and 4). This indicates that the compartmental reflection of data is quite adequate
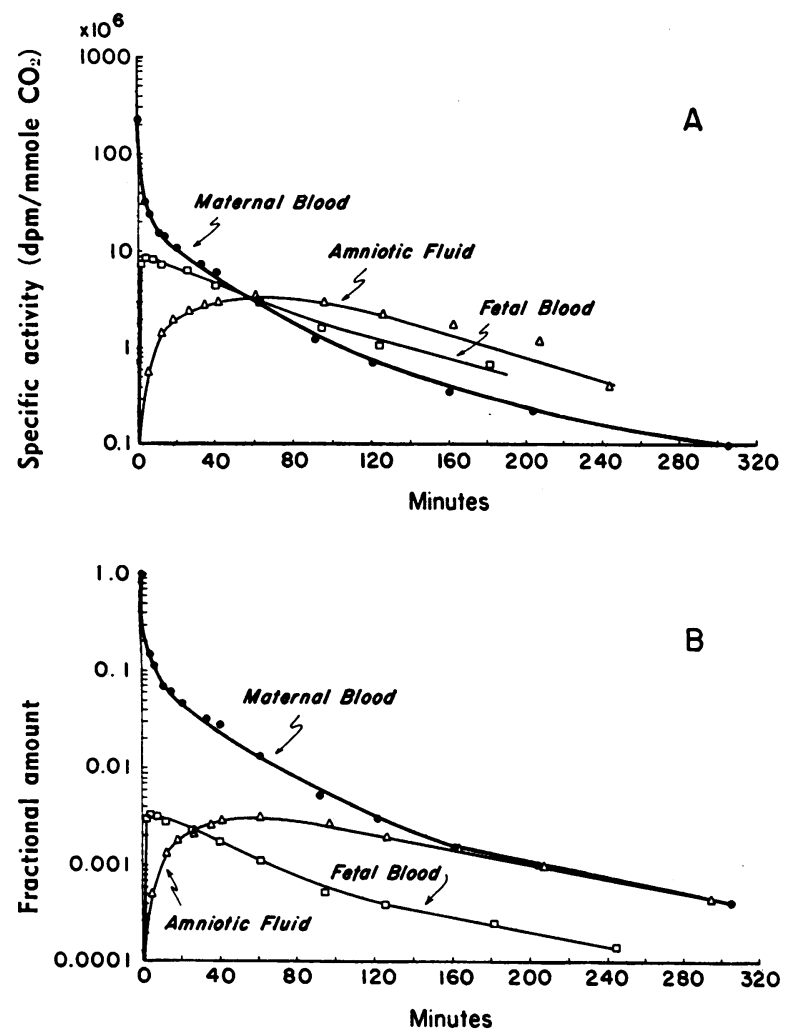

Figure $3 \mathrm{~A}$ Specific activity of ${ }^{14} \mathrm{C}$ of maternal and fetal blood and amniotic fluid as function of time after injection of $1 \mathrm{mCi}$ of $\mathrm{NaHCO}_{3}{ }^{14} \mathrm{C}$ into the maternal vein. B. Fractional amount of ${ }^{14} \mathrm{C}$ in maternal and fetal blood and amniotic fluid as function of time after injection of $1 \mathrm{mCi}$ of $\mathrm{NaHCO}_{3}-{ }^{14} \mathrm{C}$ into the maternal vein.
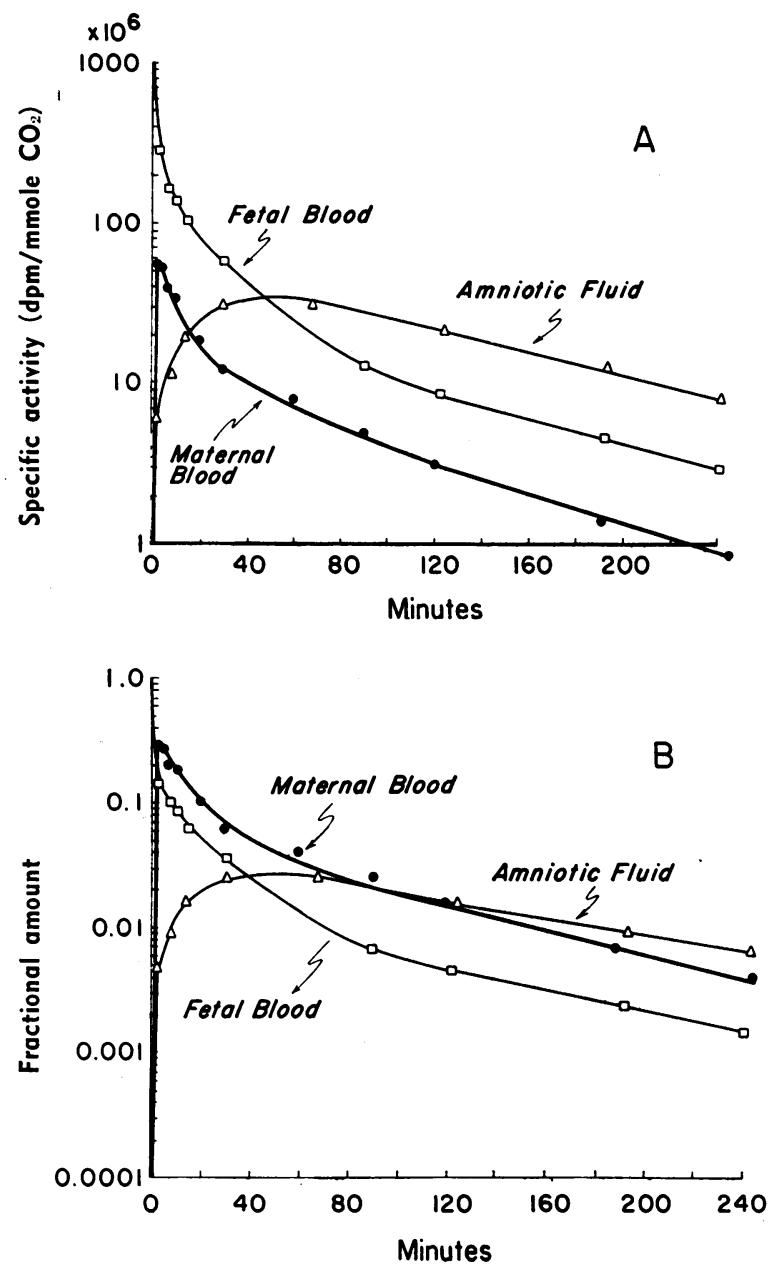

Figure $4 \mathrm{~A}$ Specific activity of ${ }^{14} \mathrm{C}$ of fetal and maternal blood and amniotic fluid as function of time after injection of $1 \mathrm{mCi}$ of $\mathrm{NaHCO}_{3}{ }^{14} \mathrm{C}$ into the interplacental vein (fetal blood stream). B. Fractional amount of ${ }^{14} \mathrm{C}$ in fetal and maternal blood and amniotic fluid as function of time after injection of $1 \mathrm{mCi}$ of $\mathrm{NaHCO}_{3}{ }^{14} \mathrm{C}$ into the interplacental vein (fetal blood stream).

(7). Because of the high diffusibility the gaseous component of the $\mathrm{CO}_{2}$ family is obviously not compartmentalized in the above terms. Since it represents only about $5 \%$ of the total it does not, however, invalidate the assumption of compartmentalization.

The concept of a compartmentalized system applies only as an approximation for biologic system, because variations in physical distributions, inhomogeneity of the media, and diffusion processes are all interrelated with chemical changes. Therefore, a compartment in this context is a space of relatively large dimensions within which distribution of the specific substance under nonsteady-state conditions, i.e. tracer, is very rapid compared to distribution between this space and others. Under the assumption that the system is in a steady state 
and consists of $\mathrm{n}$ compartments, a given set of timeactivity curves can be expressed as a sum of the respective exponential equations

$$
\mathrm{q}_{k}(\mathrm{t})=\sum_{\mathrm{i}=1}^{\mathrm{n}} \mathrm{A}_{\mathrm{ki}} \mathrm{e}^{-\alpha_{\mathrm{i}} \mathrm{t}}
$$

where $q_{k}(t)$ is the amount or fraction of the labeled $\mathrm{CO}_{2}$ in the $\mathrm{k}^{\text {th }}$ compartment at time $t$. Each exponential term on the right of this equation represents a straight line in a semilogarithmic coordinate system. Using the "peeling" technique, the exponential constants (slope $\alpha$ 's) and the coefficients (intercepts A's) can be determined. Theoretically, the number of exponential terms should correspond to the number of compartments for the system under consideration. Then, the rate of change with time will be expressed as

$$
\frac{\mathrm{dq}_{\mathrm{k}}(\mathrm{t})}{\mathrm{dt}}=\sum_{\mathrm{i}=1}^{\mathrm{n}}-\alpha_{\mathrm{i}} \mathrm{A}_{\mathrm{ki}} \mathrm{e}^{-\alpha_{\mathrm{i}} \mathrm{t}}
$$

In a steady state where the amounts of labeled and nonlabeled $\mathrm{CO}_{2}$ entering and leaving each compartment are equal, the rate of change of the amount of labeled $\mathrm{CO}_{2}$ in each compartment will be given by

$$
\frac{d q_{i}(t)}{d t}=-\lambda_{i i} q_{i}(t)+\sum_{\substack{j=1 \\ j \neq i}}^{n} \lambda_{i j} q_{j}(t) \quad(i=1,2, \ldots, n)
$$

where $q_{i}(t)=$ the amount of the labeled $\mathrm{CO}_{2}$ in the $i^{\text {th }}$ compartment at time $t ; q_{j}(t)=$ the amount of the labeled $\mathrm{CO}_{2}$ in the $\mathrm{j}^{\text {th }}$ compartment at time $t ; \lambda_{\mathrm{ii}}=$ the total turnover rate in the $\mathrm{i}^{\text {th }}$ compartment; and $\lambda_{\mathrm{ij}}$ $=$ the fractional amount of $\mathrm{CO}_{2}$ (labeled and nonlabeled) in the $j^{\text {th }}$ compartment transferred to the $i^{\text {th }}$ compartment per unit of time, i.e., a fractional transfer rate of $\mathrm{CO}_{2}$ from compartment $j$ to compartment $i$.

From equations 1,2 , and 3 and with the use of algebra of matrices, we can obtain

$$
[\lambda]=[\mathrm{A}][\alpha][\mathrm{A}]^{-1}
$$

where $[\lambda]$ and $[\mathrm{A}]$ are $\mathrm{n} \times \mathrm{n}$ matrices and $[\alpha]$ is a diagonal matrix. The transfer rates $\lambda$ 's are thus dependent on the values of $\alpha$ 's and A's, a relation first established by Hart (13).

From a knowledge of A's, $\alpha$ 's, and the boundary conditions, the number of degrees of freedom can then be deduced which gives an indication of the feasibility of solving the equation 4 . When the tracer is injected into one compartment only, the sum of coefficients for that compartment is

$$
\sum A_{1 j}=1.0
$$

and for all others

$$
\sum A_{k j}=0.0(k \neq 1) .
$$

In physiologic systems containing multiple compartments all the necessary $\alpha$ 's and A's are rarely known, since some of the compartments are not accessible. Thus it becomes necessary to use a transformation matrix to map the system within the configuration based upon the available information. The transformed $[\lambda]$ becomes

$$
\left[\lambda^{\prime}\right]=[\mathrm{P}][\lambda][\mathrm{P}]^{-1}
$$

where $\left[\lambda^{\prime}\right]$ is a similar matrix of $[\lambda]$, and $[P]$ is a transformation matrix. By means of $[\mathrm{P}]$, variables can be introduced according to the degrees of freedom.

The generating model (a lambda matrix) obtained by performing the operation in equation 4 need not correspond to a physically realizable set of $\lambda$ 's though some of them might be negative. Incorporating the constraints and the variables equal to the number of degrees of freedom, a similar matrix is obtained which represents all possible models. In this matrix the $\lambda$ 's are dependent on the new variables introduced or, if such dependence does not exist, some of them must be constant, i.e., invariants of the system. This circumstance can be used to define the realizable space, area or line according to number of degrees of freedom. This is done by setting

$$
\begin{aligned}
& \lambda_{\mathrm{ij}} \geqq 0 \\
& \lambda_{\mathrm{jj}} \geqq \sum_{\mathrm{i}=1}^{n} \lambda_{\mathrm{ij}} \text { where } \mathrm{i} \not \mathrm{j} .
\end{aligned}
$$

The region where these values overlap defines the limits for the fractional transfer rates $\lambda$ 's. This procedure of mapping, however, becomes complex when more than three compartments are involved or when pooling of compartments is not justified. Therefore, it is best to use the procedure only as a way to arrive at initial estimates of fractional transfer rates for the digital computer program SAAM-22 (Appendix III).

To determine the minimal number of compartments necessary for the model and obtain information necessary for building the model the data of the nonpregnant monkeys were analyzed. First, in Fig. 2 at least three straight lines could be drawn as shown by the "peeling" technique. This indicates that regarding the distribution of $\mathrm{CO}_{2}$ there are at least three compartments in the nonpregnant animal. Further, all the data from a single study were fitted jointly to sums of exponentials, using the digital computer program SAAM-22 (8). Three exponentials were necessary and sufficient to satisfy the data from $5 \mathrm{~min}$ to $240 \mathrm{~min}$. Hence it was assumed that the fetus has at least an equal number of compartments in addition to the physically well defined compartment of amniotic fluid. The system under consideration thus has a minimum of seven compartments.

The specific activity curve in primary compartment (maternal blood in Fig. $3 \mathrm{~A}$, fetal blood in Fig. $4 \mathrm{~A}$ ) showed a rapid decline during the first few minutes 
which corresponded to a general distribution of $\mathrm{CO}_{2}$ within the various maternal or fetal compartments. After a certain length of time, equilibration was established between them and the secondary compartments, except for that of amniotic fluid. Eventually the curve approached a straight line which presumably reflected the rate of production of endogenous carbonl dioxide. In Fig. $3 \mathrm{~A}$ the time-activity curves for mother and fetus approached each other within the first few minutes and became almost identical thereafter. It indicated a rapid transfer from mother to fetus. When ${ }^{14} \mathrm{C}$ is injected into fetal blood (Fig. 4 A), the specific activity curve for maternal blood also rose rapidly but never reached the fetal level. The lower activity of ${ }^{14} \mathrm{C}$ in maternal blood is expected due to the larger size of the compart ment and is not indicative of the low rate of transfer. This established a transfer from fetus to mother. Taken together, these two facts represent evidence for an exchange of $\mathrm{CO}_{2}$ between the maternal and fetal blood.

The concentration of ${ }^{14} \mathrm{C}$ in amniotic fluid rose gradually but ultimately exceeded that of maternal and fetal blood; from then on the three curves declined at an identical slope. In Fig. $3 \mathrm{~A}$ the specific activity curve for amniotic fluid crossed maternal and fetal curves at about $60 \mathrm{~min}$ at which time it had reached its maximum. Since maternal and fetal curves are nearly identical at

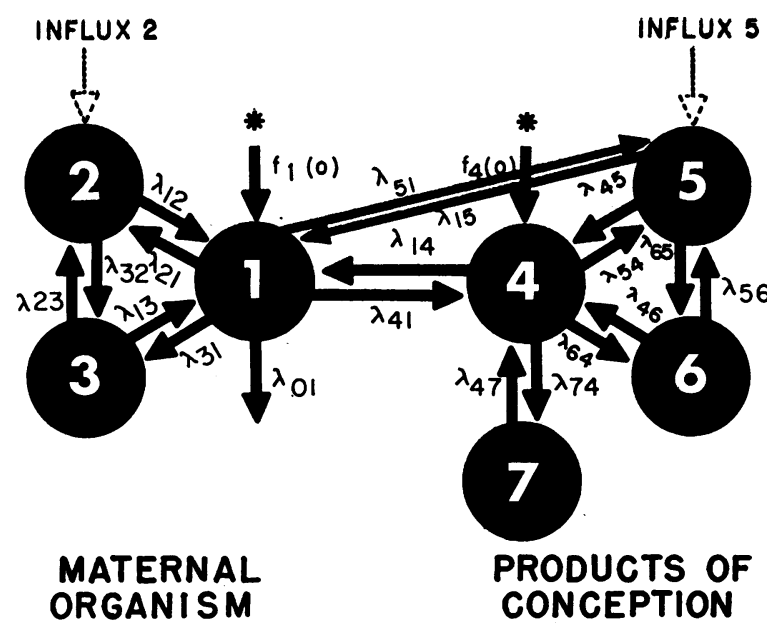

FIGURE 5 Schematic presentation of the seven-compartment model used for the estimation of the transfer rates of carbon dioxide between mother and fetus in the rhesus monkey. Compartments 1,4 , and 7 are the accessible compartments, i.e., maternal and fetal blood and amniotic fluid respectively. Compartments 2, 3 and 5, 6 are maternal and fetal subcompartments respectively. Both subsystems have their own characteristic influx rate (production rate of $\mathrm{CO}_{2}$ ). $\lambda_{1 j}$ denotes fractional transfer rate from compartment $j$ to compartment $\mathrm{i}$. The $*$ indicates the initial condition in compartment 1 or 4 at $t=0 . f_{1}(0)$ or $f_{4}(0)$ is the amount of tracer present in compartment 1 or 4 at the beginning of the measurement. $\lambda_{01}$ denotes loss of $\mathrm{CO}_{2}$ from compartment 1 to outside the system.
TABLE II

Comparison of the Initial Estimates for the Independent Adjustable Lambda Parameters with the Final Values Obtained after 10 Iterations (Experiment I)

\begin{tabular}{|c|c|c|c|c|c|c|}
\hline \multirow{2}{*}{\multicolumn{2}{|c|}{ Lambda }} & \multirow{2}{*}{\multicolumn{3}{|c|}{ Initial estimate }} & \multicolumn{2}{|c|}{ Final values } \\
\hline & & & & & & \\
\hline To & Froth & & Minima & Maxima & Value & deviation \\
\hline 4 & 5 & 0.0935600 & 0.0500 & 0.2000 & 0.08865183 & \pm 0.02489358 \\
\hline 4 & 7 & 0.0157917 & 0.0120 & 0.0170 & 0.01621956 & \pm 0.00000146 \\
\hline 2 & 1 & 0.5870000 & 0.5000 & 0.7000 & 0.60281230 & \pm 0.05765683 \\
\hline 1 & 2 & 0.0696000 & 0,0400 & 0.0800 & 0,07336304 & $\pm 0.0088202 \theta$ \\
\hline 3 & 2 & 0.0273800 & 0.0200 & 0.0400 & 0.02742380 & \pm 0.00723806 \\
\hline 0 & 2 & 0.0100000 & 0.0050 & 0.0200 & 0.01004614 & \pm 0.00642462 \\
\hline $\mathbf{0}$ & 3 & 0.0081400 & 0.0050 & 0.0200 & 0.00772685 & \pm 0.00277876 \\
\hline $\mathbf{0}$ & 1 & 0.0302700 & 0.0000 & 0.1500 & 0.03128194 & \pm 0.04987118 \\
\hline 1 & 3 & 0.0005460 & 0.0000 & 0.1000 & 0.00041189 & \pm 0.00033172 \\
\hline 5 & 4 & 0.7109000 & 0.2000 & 1.0000 & 0.70986840 & \pm 0.3741805 \\
\hline 6 & 4 & 0.0311000 & 0.0100 & 0.0900 & 0.03152570 & \pm 0.04009691 \\
\hline 6 & 5 & 0.0291200 & 0.0100 & 0.1000 & 0.02087857 & \pm 0.00495305 \\
\hline 4 & 6 & 0.0104600 & 0.0000 & 0.1000 & 0.01136830 & \pm 0.00189480 \\
\hline 4 & 1 & 0.0055000 & 0.0015 & 0.0100 & 0.00530514 & \pm 0.00103321 \\
\hline 1 & 4 & 0.7819900 & 0.5000 & 0.9000 & 0.81094570 & \pm 0.17963710 \\
\hline 5 & 1 & 0.0360000 & 0.0100 & 0.0500 & 0.03365489 & \pm 0.00832059 \\
\hline 7 & 4 & 0.0389423 & 0.0200 & 0.0400 & 0.03979820 & \pm 0.00153615 \\
\hline
\end{tabular}

this time, both maternal and fetal blood can be regarded as sources of carbon dioxide in amniotic fluid. However, in Fig. $4 \mathrm{~A}$ the specific activity curve for amniotic fluid crossed the maternal curve at about $16 \mathrm{~min}$ and continued to rise and crossed the fetal curve at about $45 \mathrm{~min}$ at its maximum. This indicates that fetal blood is the sole source of the carbon dioxide in amniotic fluid. Friedman and his associates (11) and Seeds, Bissonnette, Lim, and Behrman (14) showed that bicarbonate infused into amniotic fluid was transferred mainly into fetal blood directly, indicating the insignificance of the pathway from amniotic fluid to mother. In this study placenta and fetal membranes were regarded as a part of fetal subcompartment 5 and maternal blood as well as fetal blood must have direct pathway of $\mathrm{CO}_{2}$ exchange with this compartment. The simplest possible model of seven compartments which meets all the requirements stated above is given in Fig. 5. The transfers between the maternal blood, fetal blood, and amniotic fluid are of major interest whereas the exchange between the other maternal ( 2 and 3 ) and fetal (5 and 6) compartments, though dependent, are not of immediate significance. Since there are seven compartments, there are $7^{2}=49 \lambda^{\prime}$ s to be represented by $7 \times 7$ matrix. All these values are interrelated, and these values and their limits within which the system can be described must be found. As noted above, the system can be expressed as a set of simultaneous differential equations which are linear and time dependent.

Computational procedures and derived results. Data fitting was accomplished by means of an iterative process using the computer program SAAM-22 (8). This pro- 


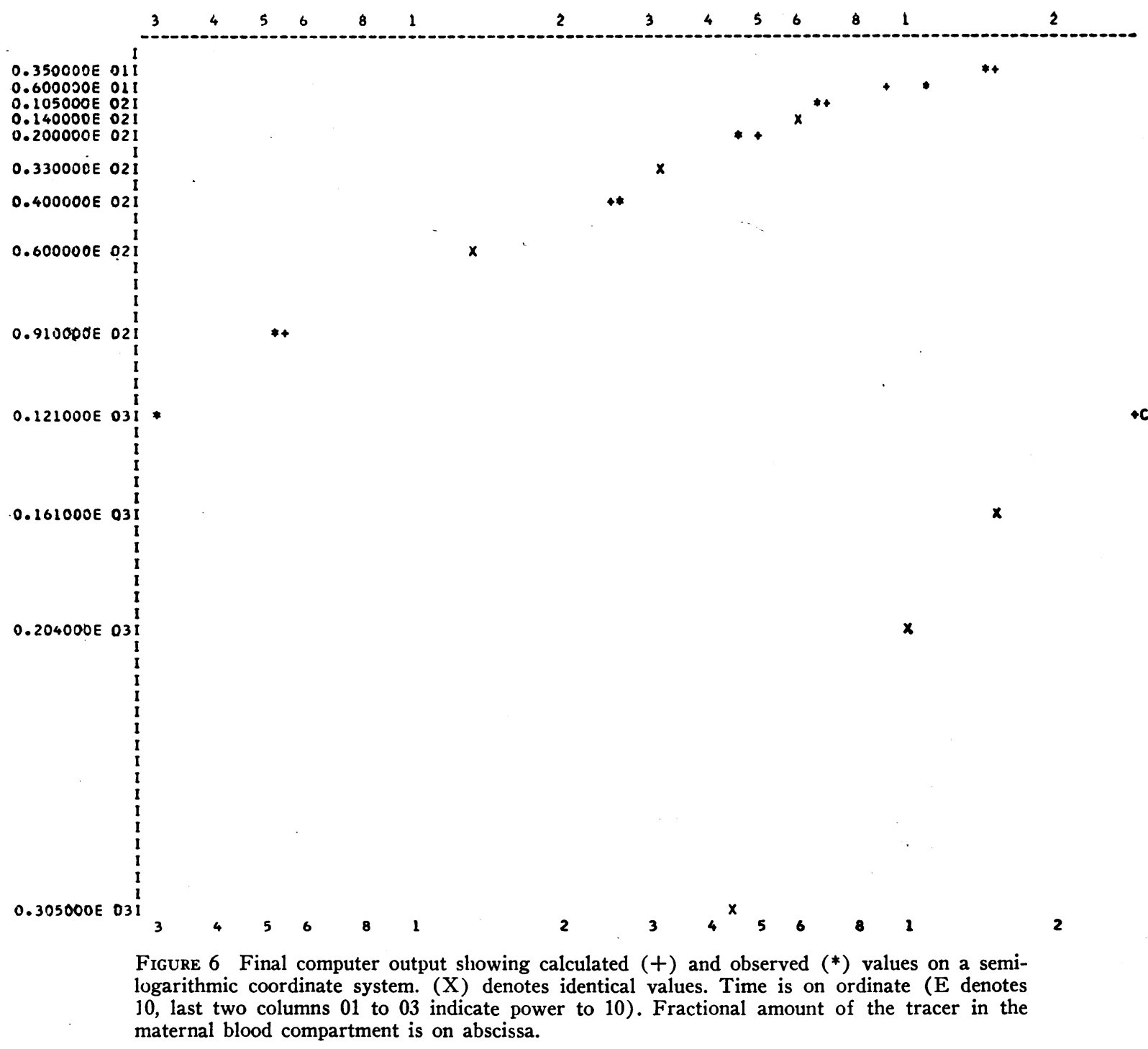

gram is designed to fit physical or mathematical models to data by adjusting the parameter values of the model repeatedly until a "best fit" is obtained. Of the many model types available for routine use in this program, the solution of linear differential equations with constant coefficients (model code 1) was used as it was best suited for the present problem.

All data from a single study were fitted simultaneously to a single set of model parameters. The data included fractional amounts of ${ }^{14} \mathrm{CO}_{2}$ of maternal and fetal blood and amniotic fluid.

By trial and error using only changes in selected parameters $\lambda$ 's over a fairly wide but reasonable range determined by a similarity transformation and mapping, the estimates of the parameters were brought within the limits where the program could be asked to iterate to adjust the parameter values until a specified degree of convergence was reached between the calculated values and data. The final values for each parameter $\lambda$ (fractional transfer rate) and their standard deviations were then printed out, and the calculated and observed values were compared numerically and graphically.

As an example, one of the experiments (experiment I) where the data obtained after injection of $1 \mathrm{mCi}$ of ${ }^{14} \mathrm{C}$-labeled bicarbonate into the maternal vein (Fig. $3 \mathrm{~A}$ and $\mathrm{B}$ ) is considered here. The fractional amounts as a function of time in three accessible compartments (maternal and fetal blood and amniotic fluid) represent the needed data, and the constraints must now be set. The initial conditions are given by the fact that at time zero compartment 1 contains all the tracer and none exists in the others. A number of possible $\lambda$ 's can be ex- 
cluded for physical reasons, since no physical relation exists between a number of maternal and fetal compartments (Fig. 5). The fetus produces $\mathrm{CO}_{2}$ (influx 5) and eliminates it by transport to the mother. Since there is no other access to the outside, all the fractional amount of $\mathrm{CO}_{2}$ leaving the fetal compartments $\left(\lambda_{01}\right.$ 's, $\left.\mathrm{i}=4,5,6\right)$ must be zero and the total amount of $\mathrm{CO}_{2}$ transferred from fetus to mother per unit of time $\rho_{M F}$ must be greater than that from mother to fetus per unit of time $\rho_{\mathrm{FM}}\left(\rho_{\mathrm{MF}}>\rho_{\mathrm{FM}}\right)$.

After a number of trials taking into consideration the various possibilities for the values of the parameters $\lambda$ 's (maxima and minima), the best estimates for the lambdas were then submitted. The number of iterations were set to nine which when completed gave a new set of $\lambda$ 's. Table II shows these values for comparison with original estimates. The solution using the iterated values for the transfer rates was an excellent match for the observed and calculated points as given in Figs. 6, 7, and 8. The computed final lambda matrix is shown in Table III (experiment I) where fractional transfer rates among various compartments are expressed in fractions per mintue. In this experiment the maternal organism and the products of gestation must have their own characteris ic influx rates $\left(\mathrm{CO}_{2}\right.$ production) which may, but need not, be proportional to their weights. The model is so designed that the influx into compartment $\mathbf{5}$ must be equal to the net transfer (the total amount $\rho$ not fractional transfer rate $\lambda$ ) between fetus and mother. A set of lambdas which are best fit for the experimental data can now be used to calculate the influx into compartments 2 and 5 as well as the ratio of all compartments by using the equation:

$$
[\lambda][\mathrm{C}]=[\mathrm{I}]
$$

where $[\mathrm{C}]$ is a column matrix of the compartment sizes and [I] is a column matrix of the influx rates.

The $\lambda$ matrix (Table III, experiment I) has 49 elements, 28 of which are zero. The sizes of three compartments (maternal and fetal blood and amniotic fluid) are known, leaving four unknown sizes of compartments. Only two influx rates which are positive are unknown, five others being zero. Therefore, there are seven equations and six unknowns, a redundance which per-

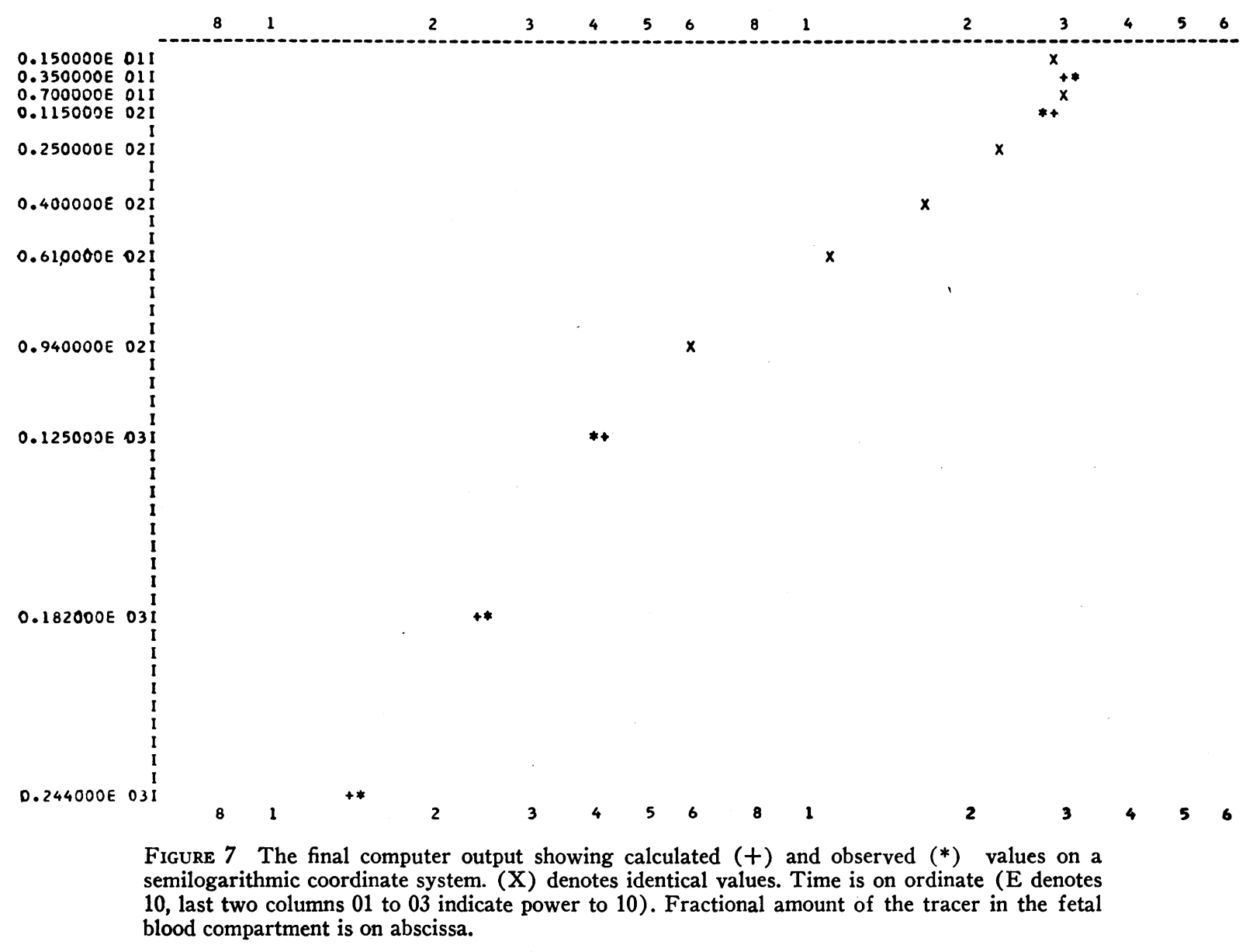




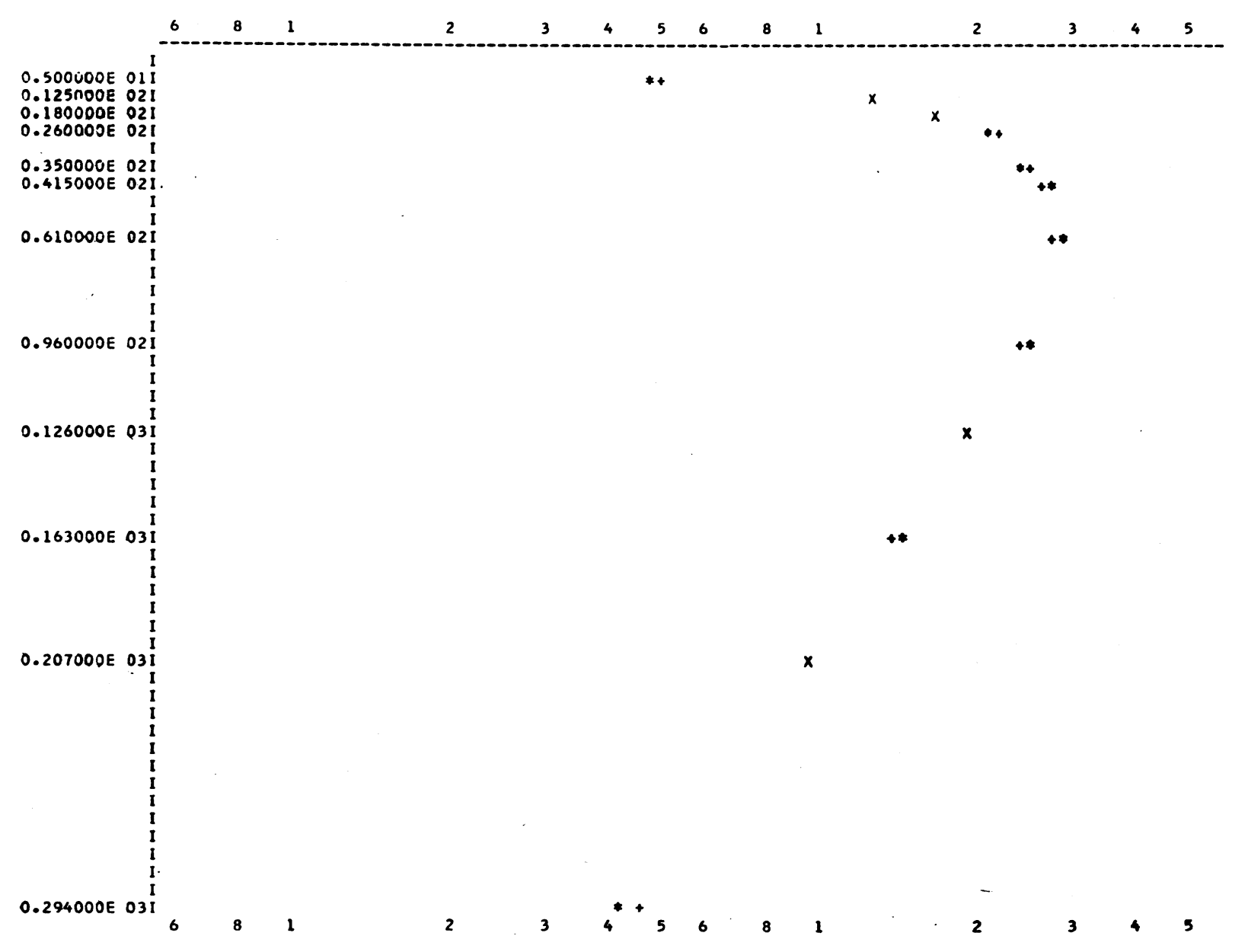

FIGURE 8 The final computer output showing calculated $(+)$ and observed $(*)$ values on a semilogarithmic coordinate system. (X) denotes identical values. Time is on ordinate ( $E$ denotes 10 , last two columns 01 to 03 indicate power to 10). Fractional amount of the tracer in the amniotic fluid compartment is on abscissa.

mits one to select the most reliable values of the known compartment sizes. Thus choosing compartments 1 and 7 (maternal blood and amniotic fluid compartments), rearranging the equation, and solving by the subroutine MATINV (matrix inversion), the values given in Table IV, experiment I, are obtained. The total amount of $\mathrm{CO}$, transferred from one compartment $\mathrm{j}$ to another $\mathrm{i}$ $\left(\rho_{11}=\lambda_{11} \cdot C_{1}\right)$ is also calculated by the computer (Table $\mathrm{V}$, experiment I). This animal weighed $8.500 \mathrm{~kg}$; the fetus, placenta, and membranes, and amniotic fluid weighed $0.480 \mathrm{~kg}, 0.080 \mathrm{~kg}$, and $0.129 \mathrm{~kg}$ respectively, i.e., $0.689 \mathrm{~kg}$ totally, leaving a net weight of $7.811 \mathrm{~kg}$ for the mother. The influx rate for the mother was $2.8133 \mathrm{mmoles} \mathrm{CO}_{2} / \mathrm{min}$ (Table IV, experiment 1 ), hence the loss of $\mathrm{CO}_{2}$ from the mother was $2.8133 / 7.811$ $=0.3602 \mathrm{mmoles} / \mathrm{kg} \cdot \mathrm{min}$. If we assume that only fetus and placenta and membranes are responsible for the in- flux of nonlabeled $\mathrm{CO}_{2}$ in compartment 5 , the rate of $\mathrm{CO} 2$ production for the products of conception would be $0.28639 /(0.480+0.080)=0.5114 \mathrm{mmoles} / \mathrm{kg} \cdot \mathrm{min}$. This value is, or should be, identical with the net transfer of $\mathrm{CO}_{2}$ from the products of conception to the mother. After one additional iteration the limits were further narrowed. The net transfer of $\mathrm{CO}_{2}$ from fetus to mother was found to be $0.2864 \pm 0.0215 \mathrm{mmoles} / \mathrm{min}$ or $0.5114 \pm 0.0384 \mathrm{mmoles} / \mathrm{kg} \cdot \mathrm{min}$ or about $11.5 \pm 0.9$ $\mathrm{ml}$ of $\mathrm{CO}_{2} / \mathrm{kg} \cdot \min$.

Similar computations were performed on three other experiments. Fractional transfer rates are shown in Table III and compartment sizes and influx rates given in Table IV. The pertinent data for each are listed in Table $\mathrm{V}$ and the final values given in Table VI. Average results of data analysis for our seven-compartment model are shown in Fig. 9. 


\section{DISCUSSION}

In this study it was assumed that ${ }^{14} \mathrm{CO}_{2}$ met the following fundamental requirements inherent to a tracer study; first, it was biologically indistinguishable from $\mathrm{CO}_{2}$ and therefore subject to the same physiological changes; secondly, it was administered in such a small, though detectable, amount as not to disturb the equilibrium of the system as a whole; and thirdly, it was distributed evenly and instantaneously in the compartment into which it was injected, and it exhibited quantitative changes in distribution into other compartments as a representative of $\mathrm{CO}_{2}$ of the system. First assumption is reasonable since ${ }^{1 i} \mathrm{CO}_{2}$ has been used successfully as a tracer for studies of the kinetics of $\mathrm{CO}_{2}$ in biological system by many investigators without isotope effects. Second assumption is also reasonable because the total amount of $\mathrm{NaH}^{14} \mathrm{CO}_{3}$ infused was 0.05 mmoles. Such a small amount of tracer should not disturb the equilibrium of the whole system. Third assumption has some limitations since some small fractions of ${ }^{14} \mathrm{CO}_{2}$ would leave the blood stream through the lungs before a single circulation is completed when the $\mathrm{NaH}^{14} \mathrm{CO}_{3}$ is injected into maternal circulation. However, considering the blood flow and the amount of $\mathrm{CO}_{2}$ in the inferior vena cava where

TABLE III

The Computed Lambda Matrix for the 7-Compartment System Schematically Shown in Fig. 5

\begin{tabular}{|c|c|c|c|c|c|c|c|}
\hline Compartment No. & 1 & 2 & 3 & 4 & 5 & 6 & 7 \\
\hline \multicolumn{8}{|l|}{ Experiment I } \\
\hline 1 & -0.67305427 & 0.07336304 & 0.00041189 & $0.81094570^{*}$ & 0.00000000 & 0.00000000 & 0.00000000 \\
\hline 2 & 0.60281230 & -0.11083290 & 0.00000000 & 0.00000000 & 0.00000000 & 0.00000000 & 0.00000000 \\
\hline 3 & 0.00000000 & 0.02742380 & -0.00813874 & 0.00000000 & 0.00000000 & 0.00000000 & 0.00000000 \\
\hline 4 & 0.00530514 & 0.00000000 & 0.00000000 & -1.59213801 & 0.08865180 & 0.01136830 & 0.01621960 \\
\hline 5 & 0.03365489 & 0.00000000 & 0.00000000 & 0.70986840 & -0.10953040 & 0.00000000 & 0.00000000 \\
\hline 6 & 0.00000000 & 0.00000000 & 0.00000000 & 0.03152570 & 0.02087857 & -0.01136800 & 0.00000000 \\
\hline 7 & 0.00000000 & 0.00000000 & 0.00000000 & 0.03979820 & 0.00000000 & 0.00000000 & -0.01621960 \\
\hline \multicolumn{8}{|l|}{ Experiment II } \\
\hline 1 & -0.89885311 & 0.15832010 & 0.00107011 & 0.71635400 & 0.00000000 & 0.00000000 & 0.00000000 \\
\hline 2 & 0.67224750 & -0.16073750 & 0.00019415 & 0.00000000 & 0.00000000 & 0.00000000 & 0.00000000 \\
\hline 3 & 0.10953540 & 0.00044294 & -0.01439515 & 0.00000000 & 0.00000000 & 0.00000000 & 0.00000000 \\
\hline 4 & 0.01661677 & 0.00000000 & 0.00000000 & -1.21995901 & 0.16625120 & 0.00797480 & 0.02534700 \\
\hline 5 & 0.04714632 & 0.00000000 & 0.00000000 & 0.43437150 & -0.17686780 & 0.00000000 & 0.00000000 \\
\hline 6 & 0.00000000 & 0.00000000 & 0.00000000 & 0.05777160 & 0.01061659 & -0.00797487 & 0.00000000 \\
\hline 7 & 0.00000000 & 0.00000000 & 0.00000000 & 0.01146190 & 0.00000000 & 0.00000000 & -0.02534700 \\
\hline \multicolumn{8}{|l|}{ Experiment III } \\
\hline 1 & -0.76518621 & 0.09692449 & 0.00045539 & 0.68890770 & 0.01806671 & 0.00000000 & 0.00000000 \\
\hline 2 & 0.66039530 & -0.12332999 & 0.00000000 & 0.00000000 & 0.00000000 & 0.00000000 & 0.00000000 \\
\hline 3 & 0.00000000 & 0.02640550 & -0.00533008 & 0.00000000 & 0.00000000 & 0.00000000 & 0.00000000 \\
\hline 4 & 0.01534630 & 0.00000000 & 0.00000000 & -0.97000926 & 0.13732730 & 0.00718314 & 0.00761140 \\
\hline 5 & 0.04260063 & 0.00000000 & 0.00000000 & 0.25568880 & -0.16770592 & 0.00000000 & 0.00000000 \\
\hline 6 & 0.00000000 & 0.00000000 & 0.00000000 & 0.01996572 & 0.01231191 & -0.00718314 & 0.00000000 \\
\hline 7 & 0.00000000 & 0.00000000 & 0.00000000 & 0.00544704 & 0.00000000 & 0.00000000 & -0.00761140 \\
\hline \multicolumn{8}{|l|}{ Experiment IV } \\
\hline 1 & -0.18746794 & 0.01630126 & 0.00000000 & 0.24767230 & 0.00000000 & 0.000 & 0.00000000 \\
\hline 2 & 0.09729273 & -0.02968570 & 0.00000000 & 0.00000000 & 0.00000000 & 0.00000000 & 0.00000000 \\
\hline 3 & 0.05949312 & 0.00001514 & -0.07650742 & 0.00000000 & 0.00000000 & 0.00000000 & 0.00000000 \\
\hline 4 & 0.00958070 & 0.00000000 & 0.00000000 & -1.27173601 & 0.25985820 & 0.01633928 & 0.00985296 \\
\hline 5 & 0.00000000 & 0.00000000 & 0.00000000 & 0.92611670 & -0.25985820 & 0.00000000 & 0.00000000 \\
\hline 6 & 0.00000000 & 0.00000000 & 0.00000000 & 0.08801362 & 0.00000000 & -0.01633928 & 0.00000000 \\
\hline 7 & 0.00000000 & 0.00000000 & 0.00000000 & 0.00993340 & 0.00000000 & 0.00000000 & -0.00985296 \\
\hline
\end{tabular}

The values are fractional transfer rates in fractions per minute from which the compartment sizes, influx rates, and total amount of $\mathrm{CO}_{2}$ transferred $f_{1}$ om one compartment to a nother are to be calculated.

${ }^{*} \lambda_{i j}$ (the value $i^{\text {th }}$ row and $j^{\text {th }}$ column) denotes the fractional transfer rate from compartment $j$ to compartment $i$, e.g., $\lambda_{14}$ $(0.81094570)$ in Experiment $I$ is the fractional transfer rate from compartment 4 (fetal blood) to compartment 1 (maternal blood), expressed in fractions per minute. 
TABLE IV

Compartment Sizes and Influx Rates Calculated from the Lambda Matrix in Table III

\begin{tabular}{|c|c|c|c|c|c|c|c|c|c|}
\hline & \multirow{2}{*}{$\begin{array}{c}\text { Com- } \\
\text { part- } \\
\text { ment } \\
\text { No. }\end{array}$} & \multicolumn{2}{|c|}{ Experiment I } & \multicolumn{2}{|c|}{ Experiment II } & \multicolumn{2}{|c|}{ Experiment III } & \multicolumn{2}{|c|}{ Experiment IV } \\
\hline & & $\begin{array}{l}\text { Compartment } \\
\text { size }\end{array}$ & $\begin{array}{l}\text { Influx } \\
\text { rate }\end{array}$ & $\begin{array}{l}\text { Compartment } \\
\text { size }\end{array}$ & $\begin{array}{l}\text { Influx } \\
\text { rate }\end{array}$ & $\begin{array}{l}\text { Compartment } \\
\text { size }\end{array}$ & $\begin{array}{l}\text { Influx } \\
\text { rate }\end{array}$ & $\begin{array}{l}\text { Compartment } \\
\text { size }\end{array}$ & $\begin{array}{l}\text { Influx } \\
\text { rate }\end{array}$ \\
\hline & & mmoles $\mathrm{CO}_{2}$ & $\begin{array}{l}\text { mmoles } \\
\mathrm{CO}_{2} / \min \end{array}$ & mmoles $\mathrm{CO}_{2}$ & $\begin{array}{l}\text { mmoles } \\
\mathrm{CO}_{2} / \min \end{array}$ & mmoles $\mathrm{CO}_{2}$ & $\begin{array}{l}\text { mmoles } \\
\mathrm{CO}_{2} / \min \end{array}$ & mmoles $\mathrm{CO}_{2}$ & $\begin{array}{l}\text { mmoles } \\
\mathrm{CO}_{2} / \min \end{array}$ \\
\hline \multirow[t]{2}{*}{$\begin{array}{l}\text { Maternal blood } \\
\text { Other maternal compartments }\end{array}$} & s 1 & $\begin{array}{r}9.59800 \\
77.58620\end{array}$ & $\begin{array}{l}0.00000 \\
2.81331\end{array}$ & $\begin{array}{l}12.37000 \\
63.06670\end{array}$ & $\begin{array}{l}0.00000 \\
1.80283\end{array}$ & $\begin{array}{l}11.51000 \\
80.12384\end{array}$ & $\begin{array}{l}0.00000 \\
2.28052\end{array}$ & $\begin{array}{r}11.99000 \\
117.86258\end{array}$ & $\begin{array}{l}0.00000 \\
2.33229\end{array}$ \\
\hline & 3 & 261.42972 & 0.00000 & 96.06622 & 0.00000 & 396.93779 & 0.00000 & 9.34690 & 0.00000 \\
\hline Fetal blood & 4 & 0.81428 & 0.00000 & 1.43963 & 0.00000 & 1.09831 & 0.00000 & 1.31800 & 0.00000 \\
\hline \multirow[t]{2}{*}{ Other fetal compartments } & $5^{*}$ & 10.84118 & 0.28639 & 8.20427 & 0.24254 & 5.75268 & 0.19360 & 5.51139 & 0.21156 \\
\hline & 6 & 22.16916 & 0.00000 & 21.35096 & 0.00000 & 12.91290 & 0.00000 & 7.09957 & 0.00000 \\
\hline Amniotic fluid & 7 & 1.99800 & 0.00000 & 0.65100 & 0.00000 & 0.78600 & 0.00000 & 1.32876 & 0.00000 \\
\hline
\end{tabular}

Compartments 1 and 7 were determined by independent means. Influx is assumed to occur only into compartments 2 and 5 .

* Compartment 5 contains placenta and fetal membranes.

the tracer was injected, the rate of elimination of $\mathrm{CO}_{2}$ through the lungs, and the circulation time, the amount of the tracer lost through the lungs in a single circulation is negligible, possibly less than $1 \%$ of the amount of the tracer injected. The difference between the assumed and actually observed rate of homogenous distribution is so small that the introduced error is much smaller than those incurred by the analytical processes and the computational procedures of iterative process to get a least square fit to the data. Therefore, even if some fractions of the injected tracer is lost before a single circulation, this would not affect this assumption significantly.

Although various studies on placental transfer of $\mathrm{CO}_{2}$ in vivo have been conducted, mainly in sheep $(15,16)$, goats $(15,17,18)$, monkeys $(19)$, and man (20), the experimental approach was entirely different from the tracer distribution method. These traditional studies were mainly concerned with determination of

TABLE V

Pertinent Data for Four Experiments Performed on Four Pregnant Rhesus Monkeys

\begin{tabular}{|c|c|c|c|c|}
\hline & \multicolumn{3}{|c|}{${ }^{14} \mathrm{C}$ injected into maternal blood } & \multirow{2}{*}{$\begin{array}{l}{ }^{14} \mathrm{C} \text { injected into } \\
\text { fetal blood } \\
\text { Experiment IV }\end{array}$} \\
\hline & Experiment I & Experiment II & Experiment III & \\
\hline Maternal weight, $\mathrm{g}$ & 8500 & 5600 & 6800 & 6180 \\
\hline Fetal weight, $g$ & 480 & 375 & 350 & 370 \\
\hline Placenta and membranes, $g$ & 80 & 100 & 88 & 110 \\
\hline Amniotic fluid volume, $m l$ & 129 & 30 & 44.9 & 79 \\
\hline Maternal blood compartment, mmoles $\mathrm{CO}_{2}$ & 9.598 & 12.370 & 11.510 & 11.990 \\
\hline Fetal blood compartment, mmoles $\mathrm{CO}_{2}$ & 0.814 & 1.440 & 1.098 & 1.318 \\
\hline Amniotic fluid compartment, mmoles $\mathrm{CO}_{2}$ & 1.998 & 0.651 & 0.786 & 1.329 \\
\hline
\end{tabular}

\begin{tabular}{|c|c|c|c|c|c|}
\hline \multicolumn{2}{|c|}{ Total amount of $\mathrm{CO}_{2}$ transferred ${ }^{*}$} & & & & \\
\hline To & From & & & & \\
\hline & & & mmole. & $/ \min$ & \\
\hline Fetal blood & Maternal blood & $0.0509(1.6) \ddagger$ & $0.2055(12.5)$ & $0.1766(29.4)$ & $0.1149(8.8)$ \\
\hline Maternal blood & Fetal blood & $0.6603(20.4)$ & $1.0313(62.5)$ & $0.7566(126.1)$ & $0.3264(24.9)$ \\
\hline Amniotic fluid & Fetal blood & $0.0324(1)$ & $0.0165(1)$ & $0.0060(1)$ & $0.0131(1)$ \\
\hline Fetal blood & Amniotic fluid & $0.0324(1)$ & $0.0165(1)$ & $0.0060(1)$ & 0.0131 (1) \\
\hline
\end{tabular}

* Total amount of $\mathrm{CO}_{2}$ transferred from compartment $i$ to $j$ can be calculated from the fractional transfer rate $\left(\lambda_{j i}\right)$ and compartment size $\left(\mathrm{C}_{\mathrm{i}}\right)$ as $\rho_{\mathrm{ji}}=\lambda_{\mathrm{ji}} \cdot \mathrm{C}_{\mathrm{i}}$.

$\ddagger$ The figures in the brackets denote the ratio in each experiment. 
the difference in concentration of $\mathrm{CO}_{2}$ between the fetal and maternal blood and (or) of arteriovenous difference in $\mathrm{CO}_{2}$ concentration on maternal side of placenta.

However, there exists a number of almost insurmountable obstacles in applying this approach to the placenta. It is difficult to determine the mean values of functional diffusion distance and area available for diffusion (21). Furthermore, $\mathrm{CO}_{2}$ concentration in uterine vein or artery and in umbilical vein or artery does not allow one to calculate the concentration at interphase with precision because of the presence of shunts (22), and the heterogeneity in composition within the intervillous space (23) makes the sampling of the representative maternal blood quite difficult. Moreover, small difference in concentration of any solute makes the use of Fick's equation unsatisfactory.

Another conventional way to calculate the quantity of $\mathrm{CO}_{2}$ produced by the fetus is by determination of arteriovenous difference of $\mathrm{CO}_{2}$ concentration on the fetal side of the placenta. This, however, requires an accurate measure of the umbilical blood flow which is difficult to obtain in a relatively undisturbed preparation.

A study of the carbon dioxide transfer using ${ }^{14} \mathrm{C}$ in the rhesus monkey has been previously conducted in this laboratory $(11,12)$. Although it yielded only qualitative interpretation of the time-activity curves, the study indicated that the isotope distribution technique was perhaps the most promising in the quantitation of $\mathrm{CO}_{2}$ transfer across the placenta. It was found that there was a rapid exchange of $\mathrm{CO}_{2}$ across the placenta and a slower exchange between fetal blood and amniotic fluid and little or no exchange between mother and amniotic fluid. This was confirmed and quantitated in the present study. In Table $\mathrm{V}$ the rate of transfer of the total amount of $\mathrm{CO}_{2}$ from fetal blood to maternal blood was 20-126 times as high as that between fetal blood and amniotic fluid. The rate from maternal blood to fetal blood was lower than that exchanged in the opposite direction, yet up to nearly 30 times as high as that between fetal blood and amniotic fluid.

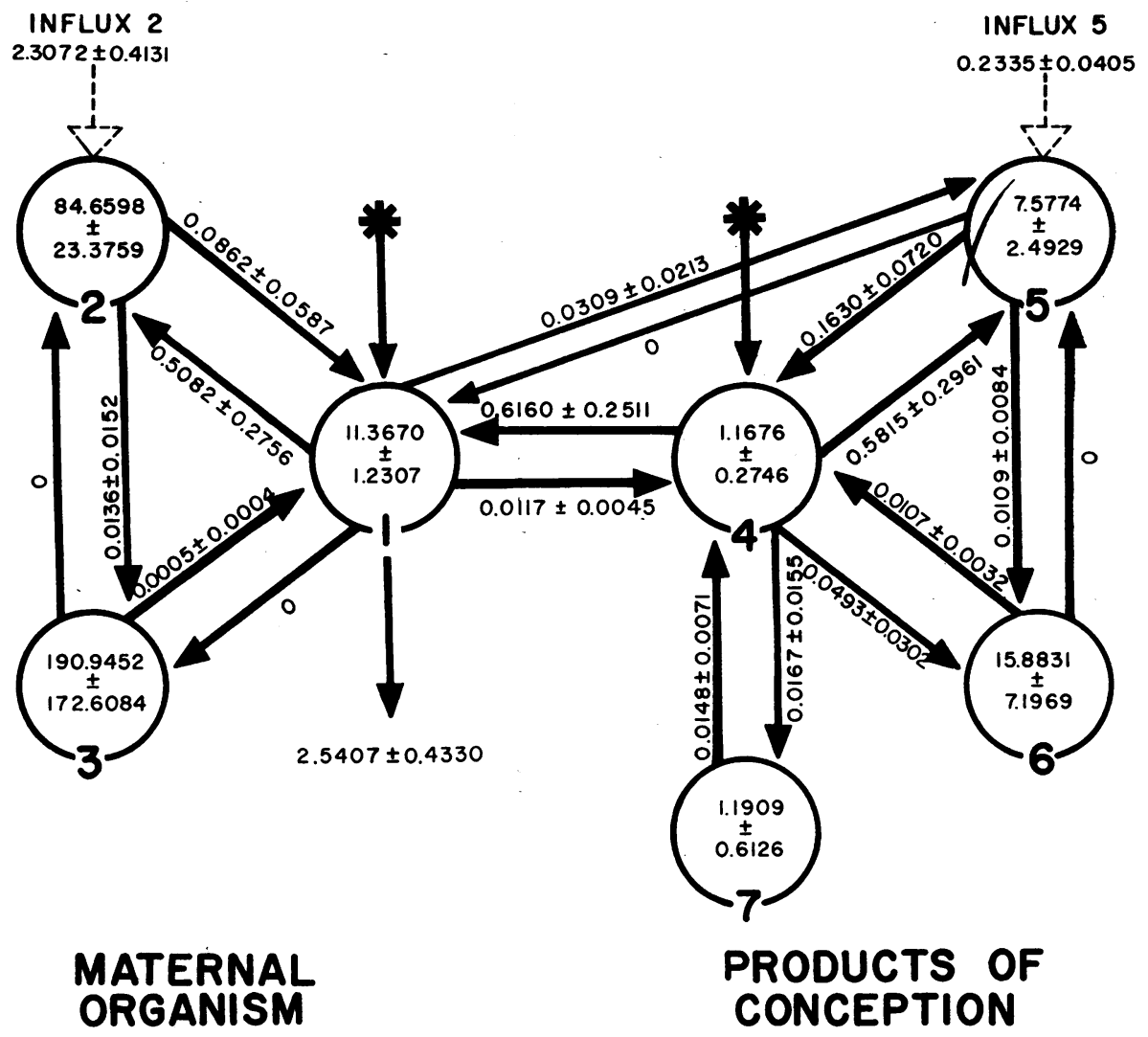

Figure 9 Average results of data analysis for the compartmental model. All values represent mean \pm 1 SD for four pregnant monkeys. To obtain the uncertainties of the mean values, divide the standard deviations by $\sqrt{4}=2$. Numbers along the arrows are fractional transfer rates, in fractions per minute. Numbers within circles are compartment sizes, in mmoles $\mathrm{CO}_{2}$. Influx into compartments 2 and 5 and loss of $\mathrm{CO}_{2}$ from compartment 1 are expressed in mmoles $\mathrm{CO}_{2}$ per minute. 
TABLE VI

Final Values of $\mathrm{CO}_{2}$ Transfer Between Fetus and Mother in Rhesus Monkeys

\begin{tabular}{lccccc}
\hline & Experiment I & Experiment II Experiment III Experiment IV & Mean \pm sD \\
\hline Influx rate into mother $\left(\mathrm{I}_{2}\right)$, mmoles $/$ min & 2.8133 & 1.8028 & 2.2805 & 2.3323 & $2.3072 \pm 0.4131$ \\
Influx rate into fetus $\left(\mathrm{I}_{6}\right)$, mmoles $/$ min & 0.2864 & 0.2425 & 0.1936 & 0.2116 & $0.2335 \pm 0.0405$ \\
$\begin{array}{l}\text { Loss of } \mathrm{CO}_{2} \text { from mother (rate of } \mathrm{CO}_{2} \text { production } \\
\text { by mother), mmoles } / \mathrm{kg} \cdot \text { min }\end{array}$ & 0.3602 & 0.3564 & 0.3610 & 0.4149 & $0.3731 \pm 0.02792^{*}$ \\
$\begin{array}{l}\text { Net transfer of } \mathrm{CO}_{2} \text { from fetus to mother (rate of } \\
\quad \mathrm{CO}_{2} \text { production by fetus), mmoles } / \mathrm{kg} \cdot \mathrm{min}\end{array}$ & 0.5114 & 0.5105 & 0.4420 & 0.4408 & $0.4762 \pm 0.04016^{*}$ \\
\hline
\end{tabular}

* Significantly different $(P<0.01)$ (Student's $t$ test).

It was also found that $\mathrm{CO}_{2}$ was transferred quite rapidly from maternal blood to fetal subcompartment 5 which contains placenta and membranes as portions. In fact, the transfer rate was about 2.5 times as fast as that from maternal blood to fetal blood. We could calculate the transfer rate of $\mathrm{CO}_{3}$ with sufficient accuracy among seven compartments designed in the pregnant monkeys by analyzing the experimental data quantitatively using the computer program SAAM 22. The determination of transfer ra:es enabled us to calculate the compartment sizes and the influx rates into fetus and mother, thus the net transfer of $\mathrm{CO}_{2}$ from fetus to mother and the loss of $\mathrm{CO}_{2}$ from mother.

As physiologic measurements are generally expected to have limitations which exert their influence on the analysis of the data, the concept of a compartmentalized system in a complex biologic system is only an approximation. Although our preparation had in actuality a nearly infinite number of physically distinct compartments, regarding $\mathrm{CO}_{2}$ distribution the seven-compartment model appeared to be satisfactory.

The present study showed that the primate fetus near term has a higher rate of the $\mathrm{CO}_{2}$ production per unit body mass than its mother. As seen in Table VI the mean value of the net transfer of $\mathrm{CO}$, from fetus to mother (the rate of $\mathrm{CO}_{2}$ production per $\mathrm{kg}$ by the fetus) is $0.4762 \pm 0.04016 \mathrm{mmoles} / \mathrm{kg} \cdot \mathrm{min}$ whereas that of loss of $\mathrm{CO}_{2}$ from mother (the rate of $\mathrm{CO}_{2}$ production per $\mathrm{kg}$ by mother) is $0.3731 \pm 0.02792 \mathrm{mmoles} / \mathrm{kg} \cdot \mathrm{min}$. The difference between the two mean values is statistically significant $(P<0.01)$. It should be noted that in the estimation of $\mathrm{CO}_{2}$ production by the fetus the placenta and fetal membranes are viewed as an integral part of fetal body. Since the rate of $\mathrm{CO}_{2}$ production can be taken as an indicator of the rate of the energy metabolism, it is suggested that the primate fetus near term has a higher metabolic rate per unit mass than its mother. This appears to be justified because under relatively constant conditions the rate of $\mathrm{CO}_{2}$ fixation by either the fetal or maternal tissue would be insignificantly low compared to the rate of $\mathrm{CO}$, production.
Recently, estimates have been provided of $\mathrm{O}_{2}$ consumption of the mature fetus in the sheep and human. Dawes, Mott, and Widdicombe (24), Acheson, Dawes, and Mott (25), and Dawes and Mott (26) obtained a mean value of $4-5 \mathrm{ml} / \mathrm{kg} \cdot \mathrm{min}$ in anesthetized mature fetal lambs. Romney, Reid, Metcalfe, and Burwell (27) reported $\mathrm{O}_{2}$ consumption of the human fetus at term of about $5.0 \mathrm{ml} / \mathrm{kg} \cdot \mathrm{min}$. Since the respiratory quotient of the fetus is assumed to be near unity these values would be almost equivalent to those of $\mathrm{CO}_{2}$. The $\mathrm{CO}_{2}$ production rate we obtained for the mature monkey fetus in this study, however, was much higher (average $10.7 \pm 0.90$ $\mathrm{ml} / \mathrm{kg} \cdot \mathrm{min})$. Dawes and Mott (26) and Romney et al. (27) concluded that $\mathrm{O}_{2}$ consumption per kilogram of the mature fetus in sheep and human was similar to that of its mother. We found the primate fetus had a higher metabolic rate than its mother near term. Their method of calculating the $\mathrm{O}_{2}$ consumption of the fetus depends on the measurement of the blood flow rate of the umbilical vessel or the uterine vessel and arteriovenous $\mathrm{O}_{2}$ difference. The accurate measurement of the blood flow of the umbilical or uterine vessel is quite difficult and the reported values must be viewed as approximations only. The determination of the difference of $\mathrm{O}_{2}$ concentration between artery and vein is also likely to invite errors. Species difference and differences in anesthesia and in surgical techniques must also be factors causing the different results in the fetal metabolic rate. However, Dawes, Jacobson, Mott, and Shelley (28) observed five newborn rhesus monkeys at an environmental temperature of $35^{\circ} \mathrm{C}$ and found the rate of $\mathrm{O}_{2}$ consumption to be $9.3-12.5 \mathrm{ml} / \mathrm{kg} \cdot \mathrm{min}$. This figure matches well that of the rate of $\mathrm{CO}_{2}$ production of the fetus in our study. This agreement in two studies in the rhesus monkey seems to indicate that species difference is the most likely cause of different results from other studies in sheep.

Judging from the findings that the metabolic rate based upon the rate of $\mathrm{CO}$ a production by the fetal monkey in our study is similar to that based upon $\mathrm{O}_{2}$ consumption by the newborn monkey found by Dawes et al. which 
was measured quite accurately because of the technical feasibility in the newborn animal, and that all the fetuses in our study survived with normal heart rates for 5-14 days after the experiment, we believe that the condition of our fetuses was within the physiological limit. However, our values are also only approximations based upon the simplified model and limited number of experiments. Further investigations would be necessary to clarify this problem.

\section{APPENDIX}

I. Fractional amount of ${ }^{14} \mathrm{C}$ in blood and all other body compartments of a nonpregnant monkey No. 397 as function of time.

\begin{tabular}{|c|c|c|}
\hline $\begin{array}{l}\text { Time } \\
(\min )\end{array}$ & $\begin{array}{l}\text { Blood compartment, } \\
\text { fractional amount }\end{array}$ & $\begin{array}{l}\text { Statistical normal- } \\
\text { ized weight }\end{array}$ \\
\hline $\begin{array}{r}5 \\
10 \\
15 \\
20 \\
25 \\
30 \\
50 \\
60 \\
75 \\
90 \\
105 \\
120 \\
150 \\
180 \\
240\end{array}$ & $\begin{array}{l}0.1071 \\
0.0710 \\
0.0542 \\
0.0427 \\
0.0359 \\
0.0312 \\
0.0157 \\
0.0140 \\
0.0069 \\
0.0050 \\
0.00475 \\
0.00400 \\
0.00263 \\
0.00217 \\
0.00132\end{array}$ & $\begin{array}{l}0.00236074 \\
0.00537167 \\
0.00921781 \\
0.0148515 \\
0.0210105 \\
0.0278174 \\
0.109857 \\
0.138156 \\
0.568759 \\
0.704009 \\
1.20016 \\
1.69241 \\
3.91485 \\
5.75052 \\
15.5410\end{array}$ \\
\hline $\begin{array}{l}\text { Time } \\
(\min )\end{array}$ & $\begin{array}{l}\text { All other compartments, } \\
\text { fractional amount }\end{array}$ & $\begin{array}{l}\text { Statistical normal- } \\
\text { ized weight }\end{array}$ \\
\hline $\begin{array}{r}5 \\
10 \\
15 \\
20 \\
25 \\
30 \\
50 \\
60 \\
75 \\
90 \\
105 \\
120 \\
150 \\
180 \\
240\end{array}$ & $\begin{array}{l}0.8329 \\
0.8290 \\
0.8058 \\
0.7773 \\
0.7541 \\
0.7288 \\
0.6243 \\
0.5660 \\
0.5131 \\
0.4550 \\
0.3953 \\
0.3460 \\
0.2674 \\
0.2078 \\
0.1287\end{array}$ & $\begin{array}{l}0.0000390338 \\
0.0000394019 \\
0.0000397634 \\
0.0000448176 \\
0.0000476177 \\
0.0000509811 \\
0.0000694768 \\
0.0000845266 \\
0.000102854 \\
0.000130799 \\
0.000173290 \\
0.000226190 \\
0.000378707 \\
0.000627098 \\
0.00163482\end{array}$ \\
\hline
\end{tabular}

Weight is calculated as $\mathrm{W}=1 / \mathrm{SD}^{2}$. After weights are assigned to all data, they are normalized so that the sum of the weights equals the number of data points having nonzero weights.

II. Fractional amount of ${ }^{14} \mathrm{C}$ in maternal and fetal blood and amniotic fluid of a pregnant monkey No. 319 (experiment I) as function of time.

$\begin{array}{ccc}\text { Time (min) } & \begin{array}{c}\text { Maternal blood, } \\ \text { fractional amount }\end{array} & \begin{array}{c}\text { Statistical normal- } \\ \text { ized weight }\end{array} \\ 3.5 & 0.146071 & 0.0000171360 \\ 6.0 & 0.108758 & 0.0000309111 \\ 10.5 & 0.0675262 & 0.0000801842 \\ 14.0 & 0.0606013 & 0.0000995567 \\ 20.0 & 0.0468996 & 0.000166224 \\ 33.0 & 0.0316106 & 0.000365906 \\ 40.0 & 0.0271074 & 0.000497576 \\ 60.0 & 0.0134210 & 0.00202984 \\ 91.0 & 0.00521010 & 0.0134692 \\ 121.0 & 0.00304887 & 0.0393329 \\ 161.0 & 0.00151761 & 0.158751 \\ 204.0 & 0.000995941 & 0.368609 \\ 305.0 & 0.000436488 & 1.91906\end{array}$

Fetal blood, Statistical normalTime (min) fractional amount ized weight

$\begin{array}{rl}1.5 & 0.00281485 \\ 3.5 & 0.00310182 \\ 7.0 & 0.00296787 \\ 11.5 & 0.00266348 \\ 25.0 & 0.00228805 \\ 40.0 & 0.00160390 \\ 61.0 & 0.00107127 \\ 94.0 & 0.000589070 \\ 125.0 & 0.000389040 \\ 182.0 & 0.000244075 \\ 244.0 & 0.000140528\end{array}$

0.0461450

0.0380015

0.0415091

0.0515388

0.0698397

0.142127

0.318595

1.05366

2.41571

6.13746

18.5144

Amniotic fluid, Statistical normal-

Time $(\mathrm{min})$ fractional amount

ized weight

5.0
12.5
18.0
26.0
35.0
41.5
61.0
96.0
126.0
163.0
207.0
294.0

0.000500030
0.00126871
0.00173660
0.00213514
0.00247976
0.00280010
0.00294943
0.00259041
0.00192165
0.00148269
0.000997704
0.000433861

1.46232

0.227149

0.121236

0.0802011

0.0594585

0.0466324

0.0420297

0.0544876

0.0990119

0.166315

0.367308

1.94237

III. Data in an open three-compartment system in a nonpregnant and a pregnant monkey for initial estimates of transfer rates in an open seven-compartment system.

From Fig. 2:

$$
\begin{aligned}
& \mathrm{A}_{11}=0.90000 \quad \mathrm{~A}_{12}=0.09000 \quad \mathrm{~A}_{13}=0.01000 \\
& \begin{aligned}
\alpha_{1} & =0.69300 \quad \alpha_{2}=0.04620 \quad \alpha_{3}=0.00866
\end{aligned}
\end{aligned}
$$

The experimental data are not very precise or numerous, and the constants were to be regarded as the best estimates. However, the information is sufficient to tell us that there are minimum of three compartments. The blood compartment is then described by the equation

$q(t)=0.90000 e^{-0.69300 t}+0.09000 e^{-0.04620 t}+0.01000 e^{-0.00866 t}$ 
Since we know all compartments exchange with each other, we set up the model as the following one,

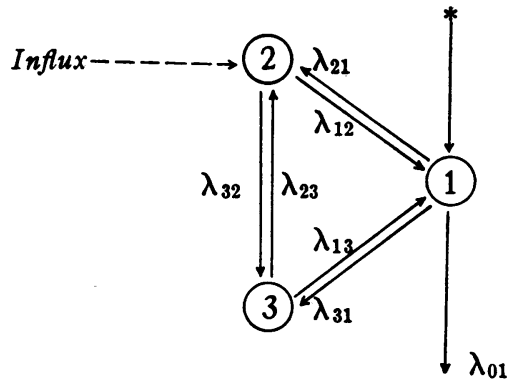

where compartment 1 is blood compartment and 2 and 3 are other compartments. Influx (production of $\mathrm{CO}_{2}$ ) is assumed to occur in compartment 2 . The * indicates the initial condition in compartment 1 at $\mathrm{t}=0 . \lambda_{01}$ denotes loss of $\mathrm{CO}_{2}$ from compartment 1 to outside the system. $\lambda_{i j}$ indicates fractional transfer rate from compartment $j$ to $i$.

The coefficients for compartment 2 and 3 are unknown, and their sum must be equal to zero at $t=0$. In order to proceed with the mapping it is only necessary to start with a matrix for the coefficients that meets the conditions.

$[A]=\left[\begin{array}{ccc}A_{11} & A_{12} & A_{13} \\ -\left(A_{22}+A_{23}\right) & A_{22} & A_{23} \\ \left(A_{22}+A_{23}\right)-A_{11} & -A_{12}-A_{22} & 1-A_{23}-A_{13}\end{array}\right]$

An arbitrary selection for $A_{22}$ and $A_{23}$ will give a generating model (a lambda matrix) that can be used to find physically realizable models compatible with the data.

Using the values derived from the graph and setting $A_{22}$ $=-0.30000$ and $\mathrm{A}_{23}=0.50000$, and $\mathrm{A}$ matrix will be

$$
[\mathrm{A}]=\left[\begin{array}{rrr}
0.90000 & 0.09000 & 0.01000 \\
-0.20000 & -0.30000 & 0.50000 \\
-0.70000 & 0.21000 & 0.49000
\end{array}\right]
$$

and $\alpha$ matrix will be

$$
[\alpha]=\left[\begin{array}{lll}
0.69300 & 0.00000 & 0.00000 \\
0.00000 & 0.04620 & 0.00000 \\
0.00000 & 0.00000 & 0.00866
\end{array}\right]
$$

A lambda matrix (generating model) calculated according to equation 4 in the text will be

$$
[\lambda]=\left[\begin{array}{rrr}
0.62794 & 0.09664 & -0.11126 \\
-0.14813 & 0.00587 & 0.00587 \\
-0.47115 & -0.09385 & 0.11405
\end{array}\right]
$$

Here the values for $\lambda_{12}$ and $\lambda_{23}$ are negative hence the model is purely theoretical and not directly applicable. However we can use this generating model for mapping purposes.

In this case the number of degrees of freedom is $3^{2}=9$; we know $A_{11}, A_{12}, A_{13}$ for compartment 1 and three $\alpha$ 's, and $\sum_{i=1}^{3}$ $A_{2 i}=0, \sum_{i=1}^{3} A_{3 i}=0$, thus the system is defined within two degrees of freedom. Selecting a suitable transformation matrix $[\mathrm{P}]$ containing two variables $\beta$ and $\gamma$,

$$
[\mathrm{P}]=\left[\begin{array}{lll}
1 & 0 & 0 \\
0 & \beta+\gamma & \beta \\
0 & 1-(\beta+\gamma) & 1-\beta
\end{array}\right]
$$

A new similar matrix $\left[\lambda^{\prime}\right]$ is obtained according to equation 5 in the text and a new $\left[\lambda^{\prime}\right]$ is expressed as a function of $\beta$ and $\gamma$ with the use of values of a generating model. Each new $\lambda^{\prime}$ is set equal to or greater than zero. This yields a plot of $\beta$ vs. $\gamma$. An area limited by lines $\lambda_{13}^{\prime}=0, \lambda_{31}^{\prime}=0, \lambda_{23}^{\prime}=0$, and $\lambda^{\prime}{ }_{32}=0$ meets the requirements. Any $\lambda^{\prime}$ obtained from $\beta$ and corresponding $\gamma$ within this area will yield a physically realizable values corresponding to the experimental data. All these calculations can be done by a computer program SAAM-22 (8). The theoretical limits for the fractional transfer rates of physically realizable models for three-compartment open system are, (in fractions per minute)

$\begin{array}{lcc} & \text { Maximum } & \text { Minimum } \\ \lambda_{12} & 0.10003 & 0.06153 \\ \lambda_{13} & 0.00257 & 0.00000 \\ \lambda_{21} & 0.61928 & 0.37463 \\ \lambda_{23} & 0.00417 & 0.00000 \\ \lambda_{31} & 0.24465 & 0.00000 \\ \lambda_{32} & 0.03850 & 0.00000\end{array}$

\begin{tabular}{|c|c|c|c|c|c|}
\hline \multirow[t]{2}{*}{ Compartments: } & \multirow[t]{2}{*}{1} & \multicolumn{2}{|c|}{2} & \multicolumn{2}{|c|}{3} \\
\hline & & $\begin{array}{c}\text { Maximum } \\
10.19858\end{array}$ & $\begin{array}{c}\text { Minimum } \\
3.44199\end{array}$ & $\begin{array}{r}\text { Maximum } \\
168.79845\end{array}$ & $\begin{array}{r}\text { Minimum } \\
21.22984\end{array}$ \\
\hline $\begin{array}{l}\text { Actual sizes: } \\
\quad\left(\mathrm{mmoles} \mathrm{CO}_{2}\right)\end{array}$ & 9.25 & 94.35 & 31.82 & 1561.4 & 196.38 \\
\hline
\end{tabular}

The ratio of the compartment sizes for all $\lambda$ 's in the defined area can be calculated according to equation 6 in the text and they are,

The influx rate to compartment 2 calculated from equation 6 in the text has the range of $0.19964-0.35109$ in fractions $/ \mathrm{min}$, or 1.85-3.25 mmoles $\mathrm{CO}_{2} / \mathrm{min}$. This represents the total elimination of $\mathrm{CO}_{2}$ from the system, which includes all mechanisms, such as respiration, metabolic processes, and urinary excretion.

Then all the data are fed into the computer program SAAM-22 (8) and data fitting is accomplished by means of an iterative process. Those values of $\lambda^{\prime}$ 's obtained above serve as initial estimates for parameters $\lambda$ 's in this program. Final values for $\lambda$ 's are (fractions per minute):

$$
\begin{array}{ll}
\lambda_{12}= & 0.09082884 \pm 0.006164936 \\
\lambda_{13}= & 0.00252647 \pm 0.001081707 \\
\lambda_{21}= & 0.4121689 \pm 0.03638044 \\
\lambda_{23}= & 0.0000104619 \pm 0.00118815 \\
\lambda_{31}= & 0.2042536 \pm 0.03023778 \\
\lambda_{32}= & 0.009234226 \pm 0.006287368
\end{array}
$$

The same process of calculation for an open three-compartment system as stated above is carried out in each data of the pregnant monkeys in order to obtain proper initial estimates for $\lambda$ 's. Thus, from Fig. $3 \mathrm{~B}$ in the experiment I we obtain:

$$
\begin{aligned}
{[A] } & =\left[\begin{array}{rrr}
0.90970 & 0.08530 & 0.00500 \\
-0.20000 & -0.30000 & 0.50000 \\
-0.70970 & 0.21470 & 0.49500
\end{array}\right] \\
{[\alpha] } & =\left[\begin{array}{rrr}
0.69300 & 0.00000 & 0.00000 \\
0.00000 & 0.03647 & 0.00000 \\
0.00000 & 0.00000 & 0.00815
\end{array}\right]
\end{aligned}
$$

and a generating model of lambda matrix calculated according to equation 4 in the text,

$$
[\lambda]=\left[\begin{array}{rrr}
0.63357 & 0.09592 & -0.10320 \\
-0.14546 & 0.00119 & 0.00850 \\
-0.47996 & -0.08896 & 0.10286
\end{array}\right]
$$

Then a similarity transformation and mapping are done. The theoretical limits for $\lambda$ 's of physically realizable models for three-compartment open system are (in fractions per minute) : 


$\begin{array}{lcc} & \text { Maximum } & \text { Minimum } \\ \lambda_{12} & 0.08662 & 0.05689 \\ \lambda_{13} & 0.00112 & 0.00000 \\ \lambda_{21} & 0.62544 & 0.40794 \\ \lambda_{23} & 0.00170 & 0.00000 \\ \lambda_{31} & 0.21748 & 0.00001 \\ \lambda_{32} & 0.02974 & 0.00000\end{array}$

The compartment sizes are calculated from equation 6 in the text and they are:

\begin{tabular}{lccccc} 
Compartments: & 1 & \multicolumn{2}{c}{2} & \multicolumn{2}{c}{3} \\
\cline { 3 - 6 } \cline { 5 - 6 } \cline { 5 - 6 } & & Maximum & Minimum & Maximum & Minimum \\
Ratio: & 1.00000 & 11.14165 & 6.48945 & 97.32467 & 23.15836 \\
$\begin{array}{c}\text { Actual sizes: } \\
\left(\text { mmoles } \mathrm{CO}_{2}\right)\end{array}$ & 9.598 & 106.938 & 62.286 & 934.122 & 222.274
\end{tabular}

The influx rate to compartment 2 calculated from equation 6 in the text has the range of $0.17404-0.36774$ in fractions per minute, or $1.670-3.530$ mmoles $\mathrm{CO}_{2} / \mathrm{min}$.

Then all the data are fed into the computer program SAAM-22 (8) and data fitting is carried out by means of an iterative process. Those values obtained above serve as initial estimates for $\lambda$ 's in this program. Final values for $\lambda$ 's obtained through this iteration can be used for initial estimates for $\lambda$ 's in the 7-compartment open system model, which are listed in Table II.

\section{ACKNOWLEDGMENTS}

This investigation was supported by the U. S. Public Health Servize Grants 1-T-1 HD 118-02, General Research Support Grant HD 00459-14 from the National Institutes of Health, and the Health Research Council of the City of New York, Investigatorship I-225.

\section{REFERENCES}

1. Dawes, G. S. 1968. Foetal and Neonatal Physiology. Year Book Medical Publishers, Inc., Chicago. 210.

2. Reynolds, S. R. M., W. M. Paul, and A. St. G. Huggett. 1954. Physiological study of the monkey fetus in utero. A procedure for blood pressure recording, blood sampling, and injection of the fetus under normal conditions. Bull. Johns Hopkins Hosp. 95: 256.

3. Plentl, A. A. 1967. Preparation of plastic $T$ catheters and devices for the collection of body fluids. J. Appl. Phy'siol. 22: 338.

4. Peters, J. P., and D. D. Van Slyke. 1932. Quantitative Clinical Chemistry. The Williams \& Wilkins Company, Baltimore. 2: 283.

5. Weyman, A. K., J. C. Williams, and A. A. Plentl. 1967. Collection of $\mathrm{C}^{14} \mathrm{O}_{2}$ for scintillation counting by a modification of the Van Slyke procedure. Anal. Biochem. 19: 441.

6. Neslen, E. D., D. L. Hutchinson, R. L. Hallet, and A. A. Plentl. 1954. Dilution methods for determination of amniotic fluid volume. Obstet. Gynecol. 3: 598.

7. Berman, M., and R. Schoenfeld. 1956. Invariants in experimental data on linear kinetics and the formulation of models. J. Appl. Phys. 27: 1361.

8. Berman, M. 1965. Compartmental analysis in kinetics. In Computer in Biomedical Research. R. W. Stacy and B. D. Waxman, editors. Academic Press Inc., New York. 2: 173 .
9. Steele, R. 1955. The retention of metabolic radioactive carbonate. Biochem. J. 60: 447.

10. Singer, R. B., J. K. Clark, E. S. Barker, A. P. Crosley, Jr., and J. R. Elkinton. 1955 The acute effects in man of rapid intravenous infusion of hypertonic sodium bicarbonate solution. Medicine. 34: 51.

11. Friedman, E. A., M. J. Gray, M. Grynfogel, D. L. Hutchinson, W. T. Kelly, and A. A. Plentl. 1960. The distribution and metabolism of $\mathrm{C}^{14}$-labeled lactic acid and bicarbonate in pregnant primates. J. Clin. Invest. 39: 227.

12. Plentl, A. A., and E. A. Friedman. 1962. Isotope tracer studies on the carbon dioxide exchange in pregnant primates. Amer. J. Obstet. Gynecol. 84: 1242.

13. Hart, H. E. 1955. Analysis of tracer experiments in nonconservative steady-state systems. Bull. Math. Biophys. 17: 87.

14. Seeds, A. E., J. M. Bissonnette, H. S. Lim, and R. E. Behrman. Changes in fetal and maternal acid-base values following amniotic fluid bircarbonate infusion. 16th Annual Meeting of the Society for Gynecologic Investigation. 47. (Abstr.)

15. Barron, D. H., and G. Meschia. 1957. The carbon dioxide concentration gradient between the fetal and maternal bloods of sheep and goats. Yale J. Biol. Med. 29: 480.

16. Kaiser, I. H., and J. N. Cummings. 1957. Hydrogen ion and hemoglobin concentration, carbon dioxide and oxygen content of blood of the pregnant ewe and foetal lamb. $J$. Appl. Physiol. 10: 484.

17. Huggett, A. St. G. 1927. Foetal blood-gas tensions and gas transfusion through the placenta of the goat. $J$. Physiol. 62: 373.

18. Keys, A. B. 1934. The carbon dioxide balance between the maternal and foetal bloods in the goat. J. Physiol. 80: 491.

19. Hellegers, A. E., C. J. Heller, R. E. Behrman, and F. C. Battaglia. 1964. Oxygen and carbon dioxide transfer across the rhesus monkey placenta (Macaca mulatta). Amer. J. Obstet. Gynecol. 88: 22.

20. Prystowsky, H., A. E. Hellegers, and P. Bruns. 1961. Fetal blood studies. XV. The carbon dioxide concentration gradient between the fetal and maternal blood of humans. Amer. J. Obstet. Gynecol. 81: 372.

21. Adamsons, K., Jr. 1965. Transport of organic substances and oxygen across the placenta. Birth Defects Original Article Series. 1: 27.

22. Bartels, H., W. Moll, and J. Metcalfe. 1962. Physiology of gas exchange in the human placenta. Amer. J. Obstet. Gynecol. $84: 1714$.

23. Hellegers, A. E. 1963. Placental exchange of oxygen and carbon dioxide. In Modern Trends in Human Reproductive Physiology. H. M. Carey, editor. Butterworths, London. 1:295.

24. Dawes, G. S., J. C. Mott, and J. G. Widdicombe. 1954. The foetal circulation in the lamb. J. Physiol. 126: 563 .

25. Acheson, G. H., G. S. Dawes, and J. C. Mott. 1957. Oxygen consumption and the arterial oxygen saturation in foetal and new-born lambs. J. Physiol. 135: 623.

26. Dawes, G. S., and J. C. Mott. 1959. The increase in oxygen consumption of the lamb after birth. J. Physiol. 146: 295 .

27. Romney, S. L., D. E. Reid, J. Metcalfe, and C. S. Burwell. 1955. Oxygen utilization by the human fetus in utero. Amer. J. Obstet. Gynecol. 70: 791.

28. Dawes, G. S., H. N. Jacobson, J. C. Mott, and H. J. Shelley. 1960. Some observations on foetal and new-born rhesus monkeys. J. Physiol. 152: 271. 